\title{
Integrating sociotechnical factors to assess efficacy of $P V$ recycling and reuse interventions
}

\section{Julien Walzberg ( $\nabla$ julien.walzberg@nrel.gov)}

National Renewable Energy Laboratory https://orcid.org/0000-0003-4630-0378

Alberta Carpenter

National Renewable Energy Laboratory

Garvin Heath

National Renewable Energy Laboratory https://orcid.org/0000-0001-6010-4475

\section{Analysis}

Keywords: Circular economy, agent-based modeling, socio-technical systems, circular strategies, machine learning, photovoltaics.

Posted Date: February 5th, 2021

DOI: https://doi.org/10.21203/rs.3.rs-151153/v1

License: (9) This work is licensed under a Creative Commons Attribution 4.0 International License.

Read Full License

Version of Record: A version of this preprint was published at Nature Energy on September 13th, 2021. See the published version at https://doi.org/10.1038/s41560-021-00888-5. 


\title{
Integrating sociotechnical factors to assess efficacy of PV recycling and reuse interventions
}

\author{
Authors: Julien Walzberg ${ }^{1 *}$, Alberta Carpenter ${ }^{1}$, Garvin A. Heath ${ }^{1}$ \\ ${ }^{1}$ National Renewable Energy Laboratory, 15013 Denver West Parkway, Golden, CO 80401, United \\ States of America \\ *Corresponding author: julien.walzberg@nrel.gov
}

\begin{abstract}
By 2050, the cumulative mass of end-of-life photovoltaic (PV) modules may reach 80 million metric tons globally. The impacts could be mitigated by circular economy (CE) strategies including module recycling, repair, and reuse. However, previous studies of PV circularity omit consideration of critical social factors. We use a novel agent-based model to integrate social aspects with techno-economic, factors-providing a more realistic assessment of circularity potential for previously studied CE interventions and assessing additional interventions that cannot be analyzed using techno-economic analysis alone. We also performed a global sensitivity analysis using a machine-learning metamodel. We show that excluding social factors underestimates the effect of lower recycling prices on PV material circularity. Interventions aimed at changing customer attitudes about used PV boost module reuse, although used modules can only satisfy a third of US demand during 2020-2050, suggesting that reuse should be complemented by recycling.
\end{abstract}

Keywords: Circular economy; agent-based modeling; socio-technical systems; circular strategies; machine learning; photovoltaics.

Word count: Abstract: 145, Manuscript: 6991 (introduction: 539, results and discussion (without captions): 3342 , methods 3111 ) 


\section{1. (Introduction)}

Soaring global deployment of solar photovoltaics (PV) could mitigate problems related to energy generation but may exacerbate other issues. PV manufacturing depletes scarce resources such as silver, tellurium, and copper ${ }^{1,2}$. For instance, silver production could peak by 2030, with a risk of demand outstripping supply around $2075^{3}$. Although minerals and metals are essential for the transition to a lowcarbon society, increased use could aggravate social and ecological problems ${ }^{4}$. Large-scale PV deployment also will produce substantial amounts of end-of-life (EOL) PV materials. By 2050, a cumulative 80 million metric tons of PV modules are expected to reach EOL globally, with 10 million metric tons in the United States (US) alone ${ }^{5}$.

Outcomes associated with increased PV deployment depend on the economic approach applied. In today's predominantly linear economy, resources are extracted to manufacture goods, which are later discarded. The alternative circular economy (CE) model could mitigate resource and ecological challenges $^{6}$ by encouraging dematerialization and the recovery and reuse of products and materials ${ }^{6,7}$. Challenges to a PV CE include low recycling rates $^{3,8}$, non-specialized PV recycling ${ }^{9}$ resulting in low material recovery rates and profits ${ }^{8}$, difficult separation of module components ${ }^{3}$, and product reuse limited by consumer awareness and attitude toward used products as well as current policy ${ }^{10}$.

Adopting a social viewpoint to complement other perspectives could increase the effectiveness of circularity-promoting interventions. Social behaviors could play a critical role in developing secondary PV markets and managing EOL PV, because psychological and behavioral traits often undermine the viability of technical solutions ${ }^{11-14}$. Sovacool and Griffiths, for instance, report that culturally rooted driving behaviors influence adoption of fuel-efficient vehicles and ridesharing services ${ }^{14}$. However, current studies of material circularity are limited to technical and economic material efficiency potentials and do not account for consumer behavior ${ }^{13,15}$. This assessment means that major changes in the way $\mathrm{CE}$ is analyzed need to be undertaken ${ }^{12,16,17}$.

We help fill this gap by incorporating social considerations into an exploration of the techno-economic, market, and policy conditions that may maximize material circularity of the dominant crystalline-silicon (c-Si) PV module technology. We apply a novel agent-based model (ABM) to represent multiple actors involved with the PV life cycle as well as social factors (attitude and peer influence) constraining CE strategies and build a machine-learning (ML) metamodel to conduct a global sensitivity analysis. An $\mathrm{ABM}$ is well suited for studying the $\mathrm{CE}$ transition because it considers temporal aspects, adopts a systemic view, and accounts for human decisions and interactions between actors ${ }^{16}$, exploiting recent advances in behavioral economics and psychology ${ }^{16,18-20}$. ABMs have been used to study CE scenarios in relation to waste management ${ }^{21-24}$, but no previous model has included secondary market dynamics 
underlying the reuse CE strategy. Many ABM studies have addressed PV adoption ${ }^{19}$, but the method has never been used to investigate renewable technologies through EOL.

By integrating social considerations, we not only analyze the factors affecting PV CE scenarios more comprehensively than previous studies have, but we also explore types of CE interventions - such as strengthening warranties for used PV modules and "seeding" used modules to encourage secondarymarket development - that cannot be assessed using techno-economic analysis alone. The result is a fuller picture of the options available for promoting PV circularity and a fuller picture of the potential effectiveness of those options separately and in combination.

\section{Results and discussion}

In our ABM, four types of agents (PV owners, installers, recyclers, and manufacturers) and five EOL management options (repair, reuse, recycling, landfilling, and storage) are defined (Supplementary Figure 1), focusing on CE strategies that have been proposed by stakeholders as likely to contribute most to the $\mathrm{CE}$ in the future ${ }^{25}$. Landfilling and storage are included because those options have been reported in the $\mathrm{US}^{26,27}$. Two purchasing options are also modeled: the purchase of new or used PV modules. For each type of agent, behavioral rules are defined based on the theory of planned behavior (TPB), which is one of the most influential theories used to explain human behavior ${ }^{13}$ and accounts for various factors affecting human decisions, such as economics and peer influence (Supplementary Table 1).

Our ABM simulates current US conditions, although changing several rules and other parameters would enable it to simulate EOL decisions for PV modules anywhere in the world. The European Union, where PV modules must be recycled at EOL based on waste electrical and electronic equipment (WEEE) regulations, is the most constrained region because only few pathways are allowed. The US is projected to have the second-largest amount of EOL modules by $2050^{5}$, and landfilling is considerably cheaper than recycling ${ }^{26}$. In this challenging environment for a PV CE, it is vital to identify the most effective and costefficient strategies or combinations of strategies to achieve maximum material circularity. To do so, we assess not only the fraction of EOL mass that avoids being landfilled (and stored), but also societal costs (i.e., net costs of manufacturers, recyclers, and installers) and recyclers and installers net revenue, because those metrics are relevant to assuring the sustainability of the CE. Dynamic factors considered include the PV module failure rate and the learning effect for module recycling - that is, the decrease in recycling costs with increasing recycled volumes due to factors such as economies of scale and technological advancement $^{28}$. Our ABM is also stochastic to account for variability in some parameters, such as landfill costs, and to enable advanced sensitivity and uncertainty analysis (Supplementary Table 1). We run 30 simulations for each scenario from 2020 to 2050 and present means in the paper's main body; we selected 
the number of simulations based on a stability analysis reported in Supplementary Figure 2. The ABM differs from similar waste-management models by including decisions related to the demand and supply sides of reuse, accounting for technical factors such as the recycling learning effect, and extending reported metrics ${ }^{21-24}$. Our approach also differs from current literature on PV EOL management in that behavioral aspects are captured to better characterize the $\mathrm{CE}$ transition. We start by providing an overview of CE scenarios, showing that many interventions besides regulations could promote circularity (Figure 1, Supplementary Table 2, Supplementary Figures 3 and 4). In the subsequent subsection, we further explore several of the interventions from Figure 1.

The baseline scenario reflects current US conditions, calibrated to available evidence, and reproduces today's low recycling and reuse rates ${ }^{8,29}$ as well as projected cumulative PV capacity and EOL modules based on the literature ${ }^{5}$. In this scenario, $500 \mathrm{GW}$ of PV will be installed in the US between 2020 and 2050, generating 9.1 million metric tons of PV waste during the same period (Supplementary Figure 5), average initial recycling costs are $\$ 28 /$ module, and average landfill costs are $\$ 1.38 /$ module. Most modules are landfilled ( $83 \%$ by mass), while $1.2 \%$ are reused and $9.5 \%$ are recycled. Only $80 \%$ of a given module's materials is recovered through recycling in the baseline scenario, because the assumed recycling process entails simple mechanical separation recovering only the aluminum frame and glass sheets from EOL modules ${ }^{9}$. Thus, the material recycling rate is $7.7 \%$, equivalent to 0.7 million metric tons cumulatively through 2050 (Figure 1, scenario i). We express all EOL rates in mass percentage of materials, including manufacturing waste, and represent cumulative amounts in 2050 unless otherwise specified. In this baseline scenario, recycling is not profitable in any year, even when accounting for the learning effect and revenue from recovered materials, so PV owners must pay a recycling fee (Supplementary Figure 5).

Techno-economic interventions could improve PV materials circularity. Research and development in recycling technologies could yield lower costs (Figure 1, scenario c), better performance, or both (Figure 1 , scenarios $b$ and $f$ ). Research and development to improve module durability would lower the amount of PV EOL materials generated (Figure 1, scenario e). Market interventions such as better warranties for recovered modules (Figure 1, scenario g), higher landfill costs (Figure 1, scenario d), "seeding" of used modules to encourage secondary market development (Figure 1, scenario h), and existing regulatory policies such as a landfill ban ${ }^{11}$ (Figure 1, scenario a) could also increase circularity. We also examine two existing business models of PV module manufacturers: extended producer responsibility and waste generator responsibility (Supplementary Figure 6). 


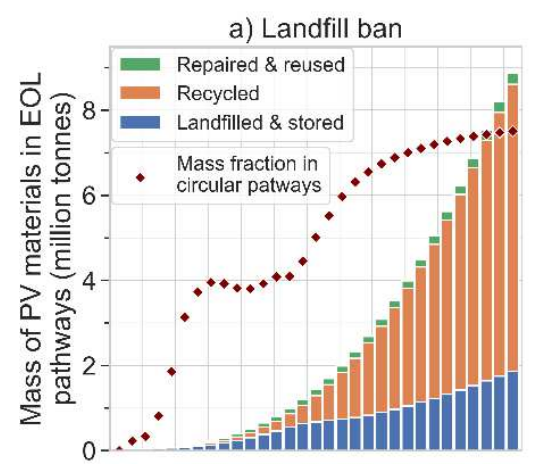

d) Higher landfill costs (\$2.75/module)

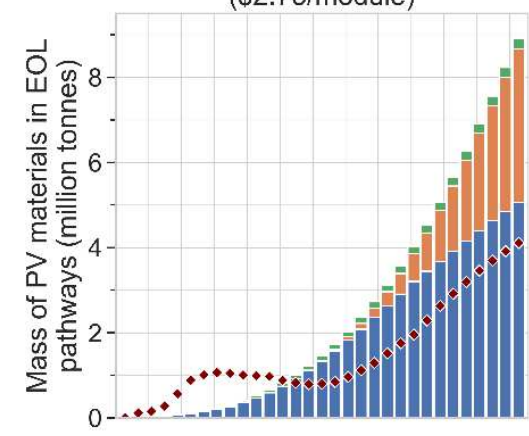

g) Reuse warranties (equal new/used attitude)

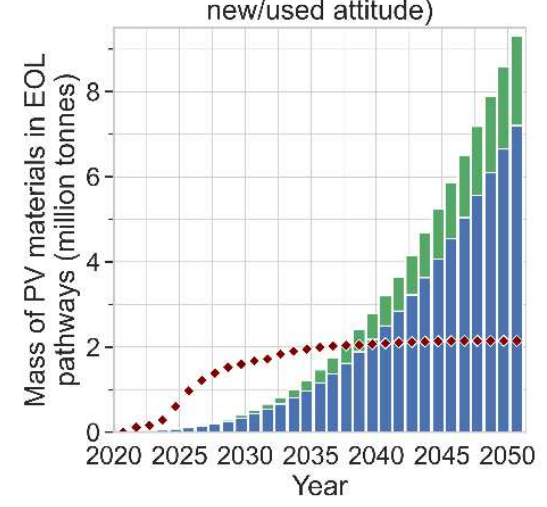

b) High material recovery $(96 \%)$ $\& \$ 18 /$ module recycling costs

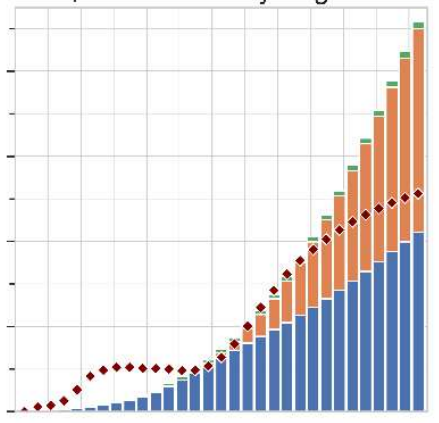

e) Improved lifetime (from 30 to 60 years in 2050)

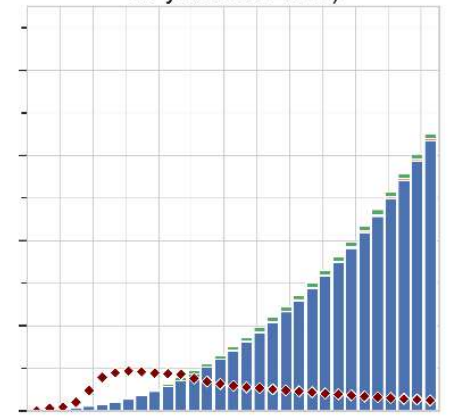

h) Seeding reuse $(5 \%$ of population per year)

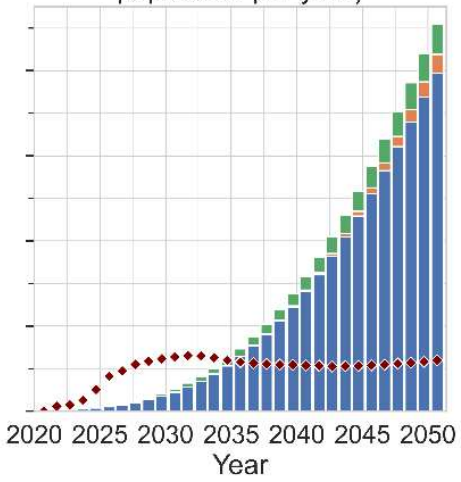

c) Lower recycling costs (\$18/module)

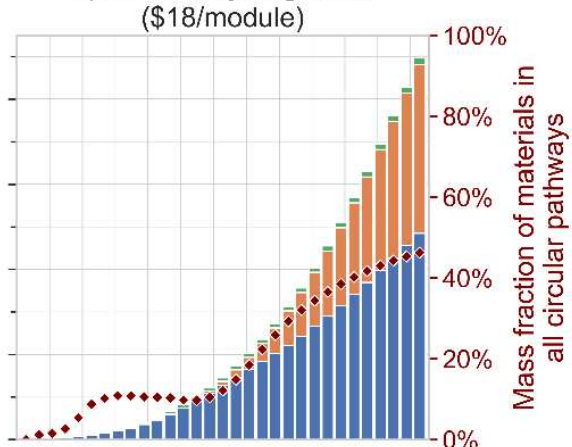

f) Improved learning effect (learning parameter $=0.6$ )

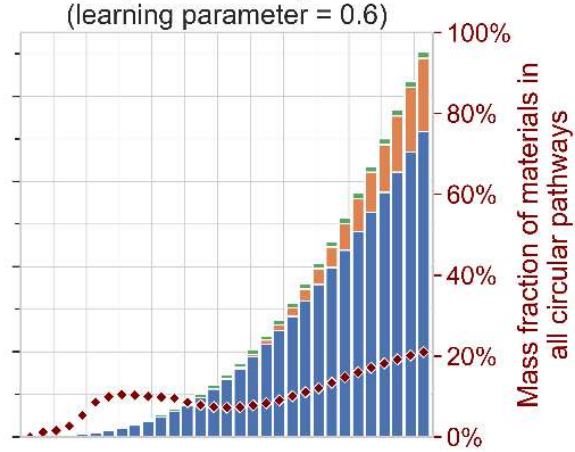

i) Baseline

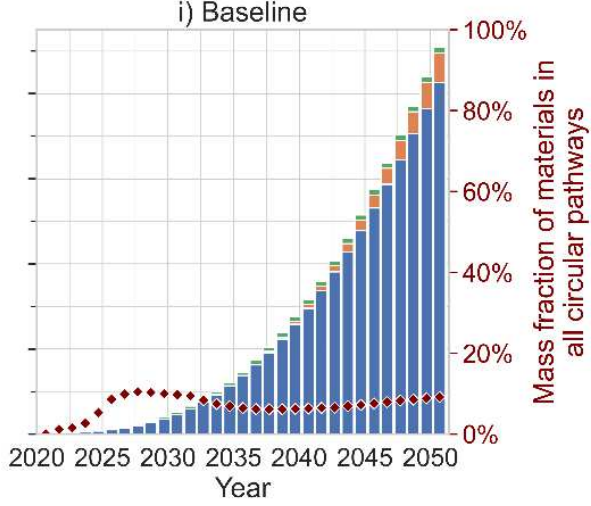

Figure 1: Various interventions could improve material circularity in the PV sector. Some interventions, including improved warranties (g) and seeding used modules (h), particularly boost module repair and reuse. Other interventions, such as lower initial recycling costs (c) and higher landfill costs (d), boost recycling. Reuse of EOL PV modules is limited by customer willingness to purchase used modules, which explains the circularity rate decline around 2035 in some scenarios, as EOL PV modules move from the reuse pathway to the landfill pathway. Although the simulations start in 2020, the generation of EOL PV modules is assumed to start from modules installed in 2000.

Exploring four interventions: lower recycling costs, higher material recovery, used module warranties, and used module seeding 
One barrier to recycling EOL PV modules is lack of profitability ${ }^{11,26,30}$. Module materials are difficult to separate and, for the most part, have low values ${ }^{30}$. For example, silver accounts for half of the material value while representing less than $1 \%$ of module mass ${ }^{5}$. Thus, recycling costs are not offset by revenues from recovered materials in the current simple mechanical processes of glass and metals recyclers in the US, leading to recycling fees of $\$ 25-\$ 30 /$ module that PV owners or installers must bear in the absence of enhanced product responsibility or take-back programs ${ }^{26}$. Some states, such as Maryland and Washington, have proposed tax incentives to overcome this issue $\mathrm{e}^{31,32}$.

Figure 2a shows the effect of varying initial (year 1) recycling costs in the ABM. The percentage of recycled EOL modules increases steeply with falling initial recycling costs before plateauing and reaching $73 \%$ recovery at zero cost. The plateau is due to several factors: 1) manufacturing waste is still landfilled, 2) for some PV owners, storage costs are null, so storage competes with free recycling, and 3) some cliques of agents reinforce each other into non-recycling behaviors through peer influence. Owing to the learning effect (Figure 2b), recycling is profitable by 2050 for each value of initial recycling costs below \$21/module (Figure 2a). With the current PV installed capacity and volumes of EOL modules, module recycling can still be considered in its infancy, and the learning effect likely will drive recycling costs down during 2020-2050. For instance, at an initial recycling cost of \$18/module (similar to the processing costs of high-recovery mechanical processes reported in the literature ${ }^{30}$ ) instead of $\$ 28 /$ module in the baseline scenario, the recycling rate increases from $7.7 \%$ to $44 \%$ (or 4.0 million metric tons) in 2050 (Figure 1 and Supplementary Figure 3). With the learning effect this initial recycling cost enables recycling to be profitable by 2050 with a net income of $\$ 0.09 / \mathrm{kg}$. The material recycling rate is also higher when recycling processes recover more materials, e.g., with the Full Recovery End of Life Photovoltaic (FRELP) process. In this process, 94\% of the silver and 97\% of the silicon in c-Si PV modules are recovered ${ }^{26}$, greatly enhancing the value of recovered materials (Figure 3 and Supplementary Figure 4).

When costs alone are included in the model, the recycling rate is always null as long as recycling is more expensive than landfilling (i.e., when initial recycling costs are above $\$ 3 /$ module) — see the "No social factors" line in Figure 2a. However, when social factors influencing PV owner decisions, such as peer influence and attitude toward recycling, are included the recycling rate increases with falling recycling costs. When social factors alone are included (the "No costs factors" line in Figure 2a), the recycling rate is overestimated or underestimated. Those results demonstrate the relevance of accounting for social aspects in the techno-economic analysis, because they may explain how and why a technology or behavior is adopted. In our case study, the positive effect of social factors on circularity when initial recycling costs are high shows the potential importance of nurturing early adopters of recycling behaviors who create a trend for other PV owners to follow. 
One strategy to increase recycling is providing a subsidy until a recycling rate target is achieved. Our simulations indicate that a larger initial subsidy can be less costly than a smaller subsidy, because it engages more PV owners to recycle earlier (Figure 2c). Moreover, the learning effect supports recycling behaviors by lowering costs further, which leads to more PV owners adopting the recycling pathway. Overall, if the stream of EOL modules reaching recyclers keeps increasing (which is likely), the learning effect could spur profitable recycling without subsidies. In our simulations, a $20 \%$ recycling target can be reached earlier with an $\$ 18 /$ module subsidy (12 years) than with a $\$ 10 /$ module subsidy (18 years), limiting the period over which subsidies must be provided. The simulations show that a yearly recycled volume above 15,000 metric tons of EOL modules could make recycling profitable owing to the learning effect, a threshold value in line with the literature ${ }^{33}$. High subsidies to encourage recycling and exploit the learning effect are a relevant strategy, but the results depend strongly on the presence of a sufficient learning effect. Thus, a subsidy program could benefit from establishing performance targets that verify continuous improvement of recycling processes, ensuring that recycling costs do not return to original levels once subsidies stop. 


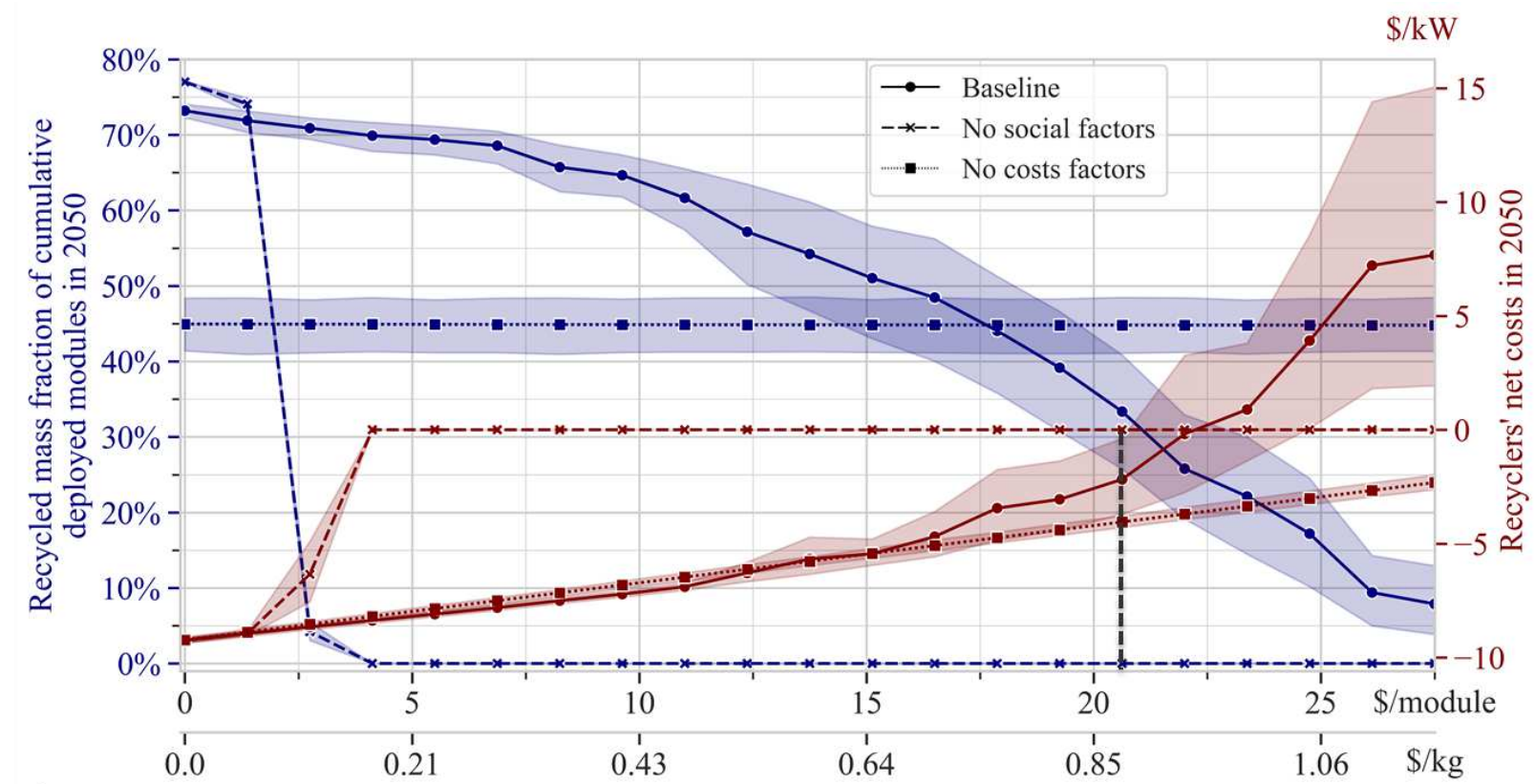

a)

Initial recycling costs in 2020

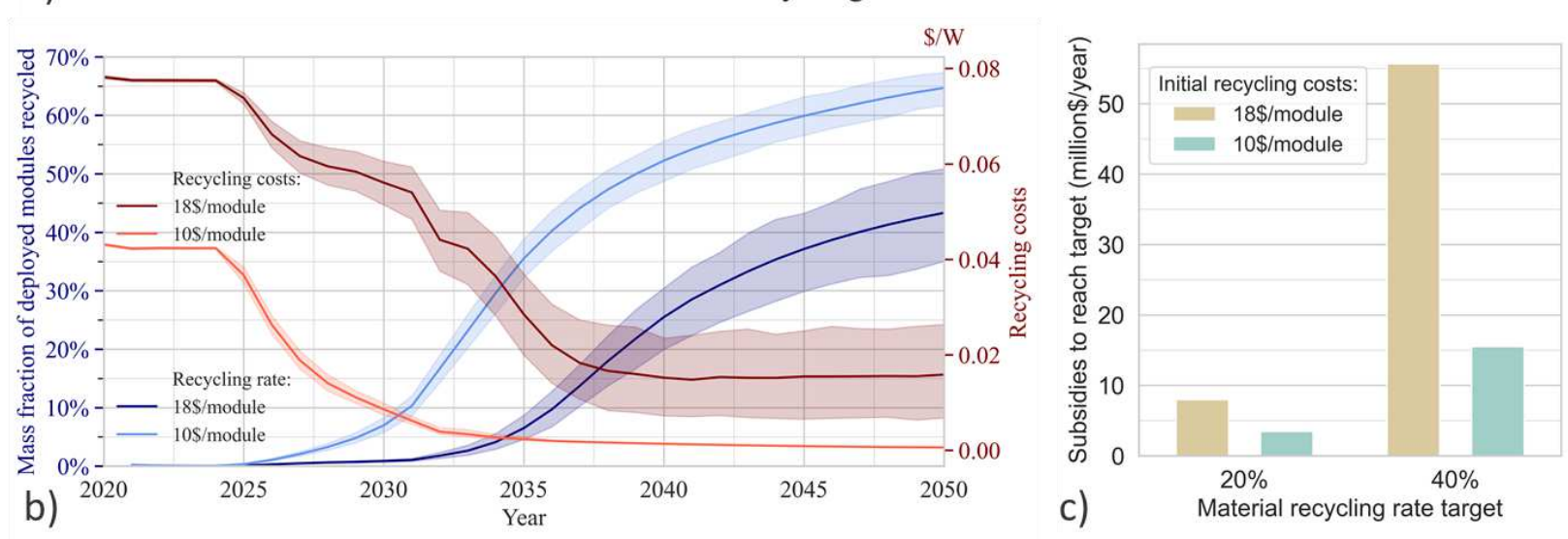

Figure 2: a) In the baseline scenario, the volume of materials recycled (cumulative total in 2050) quickly increases with falling initial recycling costs before reaching a plateau. Not accounting for economic factors (costs of recycling for PV owners) and social factors (attitude and peer influence)

misrepresents the effect of lower initial recycling costs on the volume of materials recycled.

Recycling is profitable (provides negative net costs, i.e., recycling costs minus value of recovered materials) by 2050 for initial recycling costs of $\$ 21 /$ module or less (black dashed line). Shaded areas represent $95 \%$ confidence intervals. b) Recycling costs decrease with the amount of PV modules being recycled. Shaded areas represent $95 \%$ confidence intervals. See Supplementary Figure 7 for a y-axis in $\$ / \mathrm{kg}$. c) High initial subsidies (initial recycling costs of $\$ 10 /$ module) boost recycling and help recyclers be profitable (due to the learning effect) more quickly than low subsidies (initial recycling costs of $\$ 18 /$ module), resulting in lower overall costs for the subsidy provider ( $\$ 16$ million/year instead of $\$ 56$ million/year to reach a $40 \%$ recycling rate). 
Recycling profitability could be increased through research and development in technologies that enable recovery of more valuable materials - such as silver, copper, and silicon-from EOL modules. Highrecovery mechanical processes can enable higher material recovery, up to $97 \%$ of the total mass using the FRELP process ${ }^{26}$; however, in contrast with thermal recycling processes, such mechanical processes typically recover lower-quality materials with less value and usefulness than they had in the original module $^{3}$. Figure 3 a shows shares of modules in each EOL pathway and recycler net income assuming materials recovery fractions from the FRELP process ${ }^{26}$ and an initial recycling cost of $\$ 18 /$ module ${ }^{30}$. FRELP recovers $20 \%$ more materials per module than the baseline scenario and significantly increases recovered material value owing to silver and silicon recovery (Supplementary Table 1). This economic benefit is likely to weaken in the future, however, as innovation causes silver and silicon to constitute progressively smaller mass fractions in c-Si PV modules ${ }^{5}$; our analysis does not consider this trend because of the high associated uncertainty.

Recycler cumulative net income in 2050 increases from \$296 million in the simple mechanical process scenario to $\$ 1.6$ billion in the FRELP scenario. Moreover, recycling becomes profitable earlier (2032 instead of 2037), with recycler net income reaching $\$ 0.42 / \mathrm{kg}$ in 2050 . Figure 3 b shows the synergistic effect on recovered material value of lower initial recycling costs (which spur recycling among PV owners) and higher total material recovery fractions. Our simulations also show that some EOL modules are stored for a short period, leading to a small, relatively constant share of stored modules as PV owners and installers wait for cheaper and more accessible recycling options or the accumulation of quantities that are more economical to ship and recycle ${ }^{26}$.
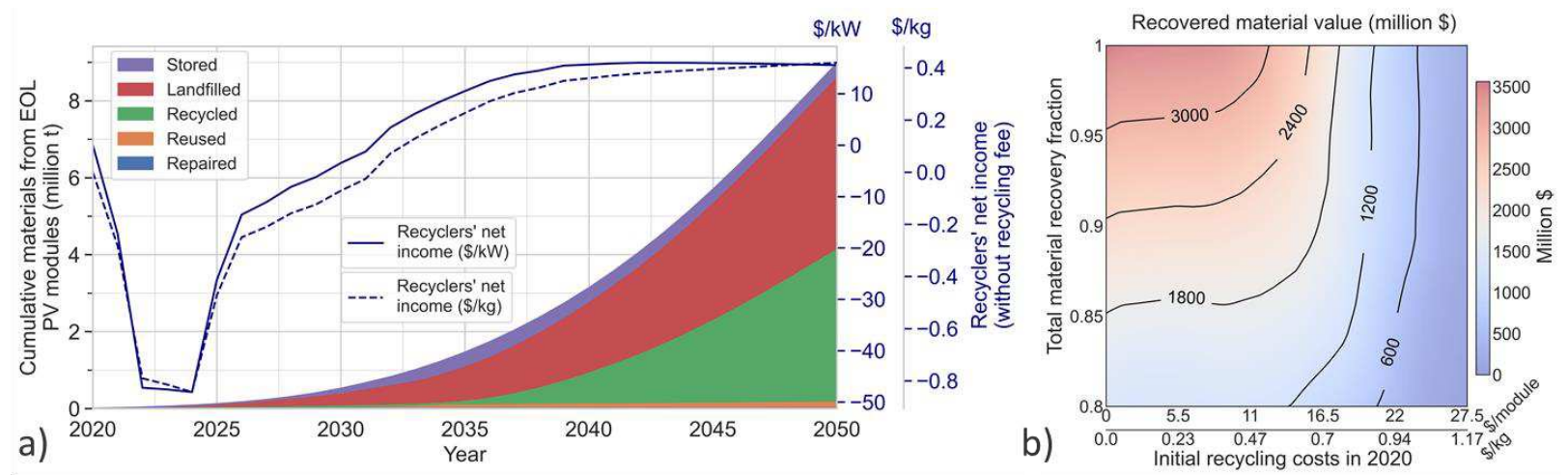

Figure 3: a) Cumulative materials from EOL PV modules and recycler net income assuming use of the FRELP process and an initial recycling cost of $\$ 18 /$ module. The dip in recycler net income is due to initially unprofitable recycling. Still, with the low initial recycling cost and high recovery of materials (including silver and silicon), recycler cumulative net income reaches $\$ 1.6$ billion, and net income is $\$ 0.42 / \mathrm{kg}$, in 2050. b) Cumulative recovered material value in 2050 . High materials recovery and low initial recycling costs have a synergistic effect on value generation, but the synergy diminishes as the 
initial recycling costs is very high or very low. For instance, at an initial recycling cost of $\$ 16 /$ module, a $13 \%$ increase from an $80 \%$ material recovery fraction roughly doubles the recovered material value.

Improved warranties for used modules could promote secondary markets ${ }^{11}$. The reuse rate increases from $1.2 \%$ to $23 \%$ (by 2.1 million metric tons) when assuming that warranties give PV owners an equivalent attitude toward used and new modules ${ }^{10}$ (Figure 1, scenario g, and Figure 4a). However, this assumption also decreases the recycling rate from $7.7 \%$ to less than $1 \%$. Figure $4 \mathrm{~b}$ shows that a $23 \%$ reuse rate only covers a small portion of projected PV demand. Even with an ambitious $89 \%$ reuse rate — set by removing all constraints to reuse except that modules can only be reused once-only a third of PV demand is met with used modules, highlighting the reuse strategy's limitation. This result is explained by the projected growth of PV demand and the imperfect substitution of used modules for new modules (due to lower power efficiency and lifetime ${ }^{34}$ ); see Supplementary Table 1 . Once reused, modules still must be managed at the end of their second life, so developing other circular pathways such as recycling or lifetime extension is critical.

In practice, improved warranties may be insufficient to improve PV owner attitudes toward used modules, because other factors, such as safety concerns or aesthetic preferences, may intervene. Thus, other strategies to promote secondary markets should be considered. For instance, short-term "seeding"providing free modules and installation to some PV owners- has proven to be an effective strategy ${ }^{35}$ that could develop secondary markets for PV through the peer effect (Figure 1, scenario h). Such a seeding strategy applied to $5.0 \%$ of PV owners (i.e., at least $5.0 \%$ of PV owners have used modules each year) enhances the reuse rate from $1.2 \%$ to $6.9 \%$ but lowers the recycling rate from $7.7 \%$ to $4.7 \%$ (Figure 1 and Supplementary Figure 3). A similar strategy, in which $10 \%$ of PV owners pay a lower initial recycling fee (\$18/module), increases the material recycling rate to $21 \%$ (Supplementary Figure 8).
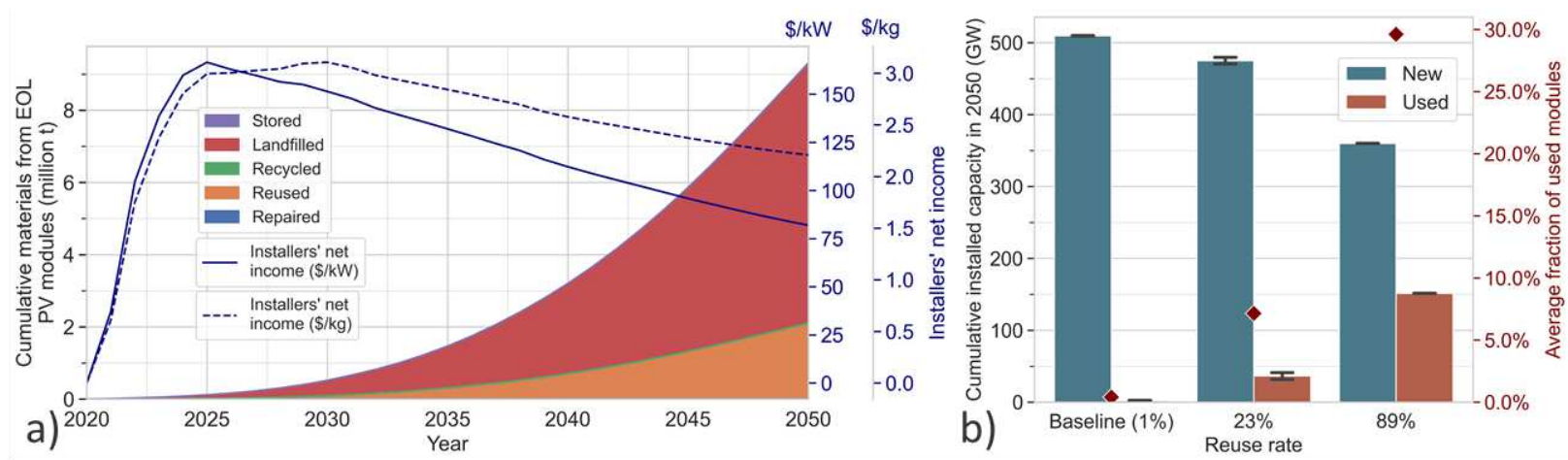

Figure 4: a) Cumulative materials from EOL PV modules and installer net income assuming improved warranties give PV owners an equivalent attitude toward used and new modules, showing substantial module reuse. Installer cumulative net income is $\$ 3.5$ billion, and net income is $\$ 2.2 / \mathrm{kg}$, in 2050 . 
After 2025, the net income per module decreases as innovation reduces PV module costs. b) Cumulative installed capacities of used and new modules in 2050 for various reuse rates obtained with our simulations; red diamonds represent the average fraction of used modules. In an ideal reuse case (89\% reuse bars in the Figure), modules landfilled after their second life represent almost $10 \%$ of the cumulative EOL PV modules in 2050. Error bars represent 95\% confidence intervals.

\section{Sensitivity analysis and combined interventions}

We use a ML metamodel of the ABM to conduct a variance-based sensitivity analysis and explore the ABM parameter space at higher speed. Figure 5 presents the first- and total-order Sobol indices for some parameters underlying the techno-economic and social interventions presented thus far. Initial recycling costs, landfill costs, and the learning effect are most important to the module circularity rate, with contributions of $48 \%, 33 \%$, and $4 \%$ to the total variance in results, respectively (see Supplementary Table 3). Attitude toward used modules has a smaller but notable effect. Although some parameters present higher-order effects, the parameters rank similarly. However, the rankings change when examining output metrics other than the material circularity rate, such as the reuse rate or societal costs (see Supplementary Table 3 and Supplementary Figures 9-11). Finally, significant second-order interactions exist between initial recycling costs and other parameters (see Supplementary Table 4).

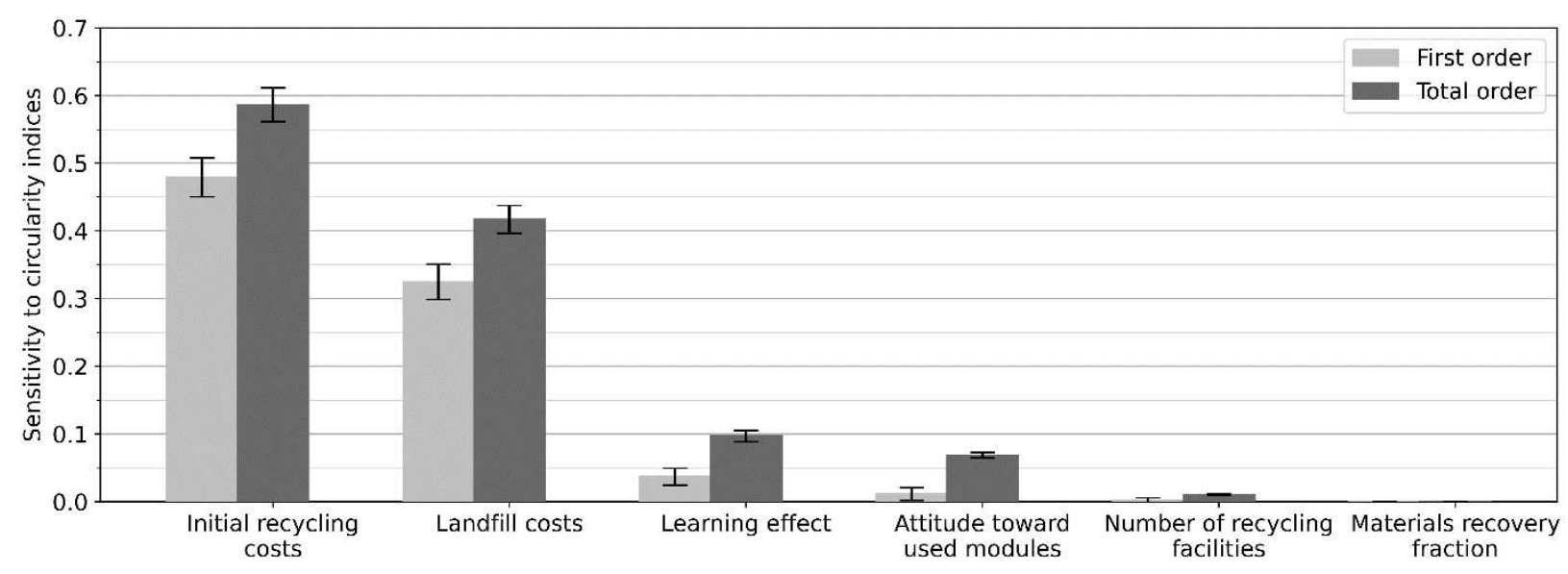

Figure 5: Parameter importance for EOL PV module circularity in the ABM, categorical parameters such as the landfill ban excluded. The $y$-axis shows the first- and total-order Sobol indices on the effect of a parameter on EOL PV module circularity. Error bars show 95\% confidence intervals.

Figure 6 presents the interaction effects between initial recycling costs and four other parameters: landfill cost, attitude toward used modules, learning parameter, and number of recycling facilities. Increments of the learning parameter and landfill cost boost the effect of decreasing initial recycling costs on material circularity (Figure 6a and 6c). For instance, with initial recycling costs of $\$ 10 /$ module, raising the landfill 
cost from $\$ 1.38 /$ module to $\$ 2.76 /$ module increases the material circularity rate from about $60 \%$ to $70 \%$ (Figure 6a). Because the reuse and recycling pathways compete, combining a more positive attitude toward used modules with lower recycling costs does not enhance the volume of PV materials diverted from landfills and storage (Figure 6b). Transportation costs are negligible compared with recycling costs, so having fewer facilities increases the material circularity rate slightly owing to an enhanced learning effect (Figure 6d). Finally, as with the sensitivity indices (Figure 5), the results are different when examining other output metrics (Supplementary Figures 12-13).
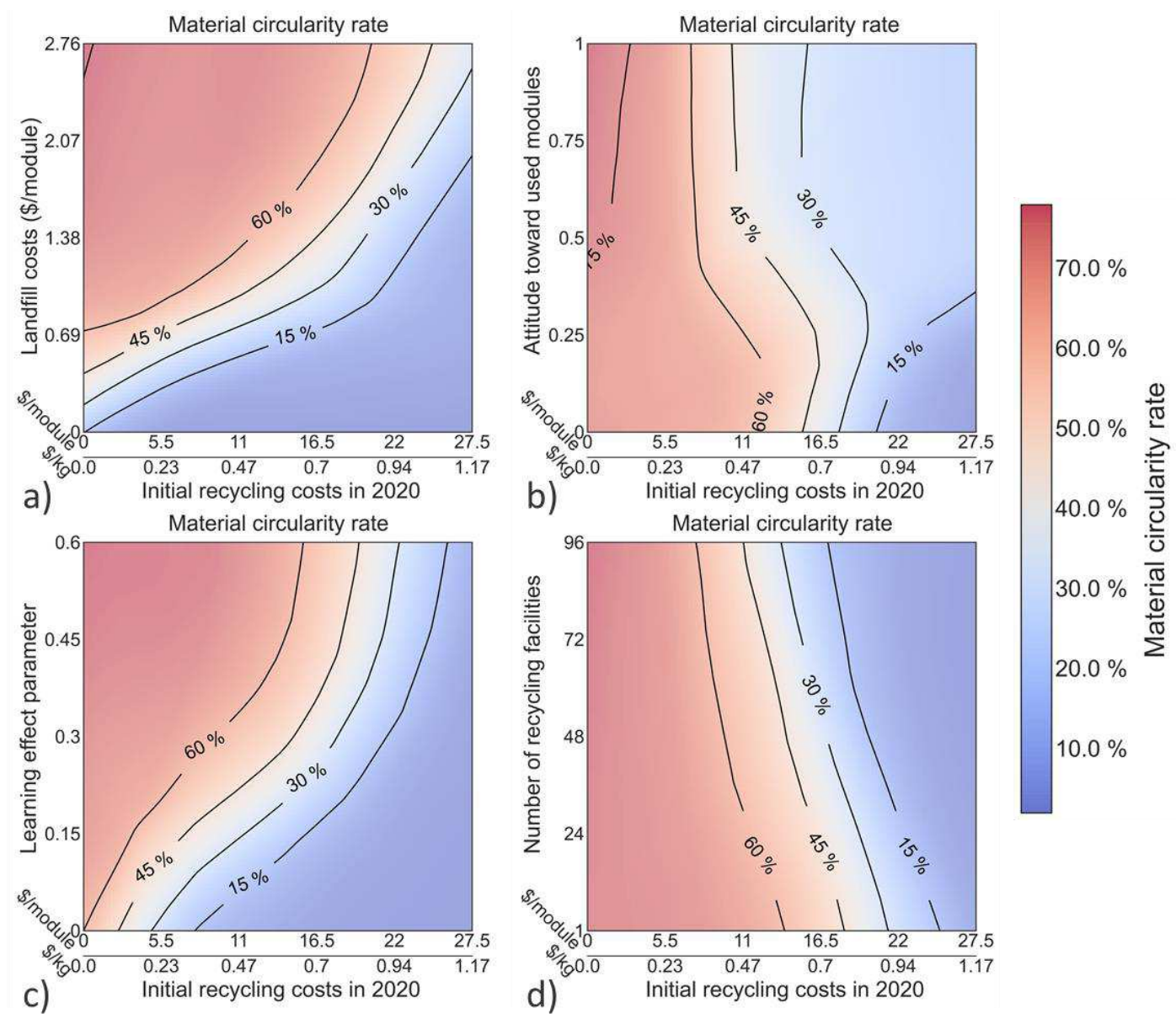

Figure 6: Fractions of PV module materials in circular pathways in 2050 as a function of the initial recycling costs (x-axis) and a) landfill costs, b) attitude toward used modules, c) learning effect parameter, and d) number of recycling facilities (y-axis).

Figure 6 also highlights that different intervention combinations may yield the same results (i.e., equifinality). For instance, initial recycling costs of $\$ 18 /$ module combined with landfill costs of $\$ 2 /$ module yield a $45 \%$ circularity rate, as do initial recycling costs of $\$ 13 /$ module combined with 48 recycling facilities. Using the ML metamodel, we designed an experiment to identify the parameter combinations maximizing circularity rate while minimizing societal costs (Supplementary Table 5). 
Overall, combining low recycling costs, high landfill costs, and high learning effect yields the best result in the $\mathrm{ABM}$, suggesting that combining interventions might be the most promising strategy to increase PV circularity at the lowest costs.

\section{Limitations}

Our results should be understood as estimates of how applying CE principles could affect EOL management of PV modules, instead of robust predictions. The ABM uses various sources as inputs, including some outside the PV sector (e.g., electronic waste literature) owing to the limited availability of primary data. Moreover, because some data variability is unknown, we approximate them using probability distributions, which adds uncertainty to the results (Supplementary Table 1). Although we use the TPB to better represent human decisions related to EOL management, factors not included in the theory may affect stakeholder decisions. In addition, we simplify stakeholders as constituting four broad categories (PV owners, installers, recyclers, and manufacturers); in the real world, the decisions of intermediary actors (e.g., brokers, insurers) may also affect PV circularity.

We limit the number of PV owner agents to a thousand, whereas more than 1 million real-world PV systems are in the $\mathrm{US}^{36}$. Moreover, PV owners are not geographically characterized, albeit related through a social network. Although we use distributions to represent some geographical disparity, we distribute total installed PV capacity evenly between agents. Combining this ABM with a distributed PV model with better spatial resolution, such as the National Renewable Energy Laboratory's Distributed Generation Market Demand (dGen) model, could yield useful insights ${ }^{37}$.

\section{Implications}

Our study yields several implications for PV circularity. First, our results suggest that CE strategies compete, in line with the literature ${ }^{38}$. Thus, CE programs should be based on adoption rates for all circular pathways rather than focusing on one CE strategy. Second, for reuse to be effective, the used product supply must match demand, and therefore secondary markets must be mature ${ }^{39}$. For example, only when PV owner attitudes toward used modules improve (e.g., through warranties) does demand grow and start substantially absorbing used module supplies. Improving reuse is critical from an energy perspective, because recycling destroys most of the embedded energy of products ${ }^{40,41}$. However, owing to growing PV demand as well as the lower efficiency and lifetime of used modules, even a $100 \%$ reuse rate could not satisfy PV demand, so recycling must be developed in concert with reuse initiatives.

Our results also highlight the critical roles of the learning effect and total recovery fraction of materials to achieve profitable recycling (Figure 1), in line with existing literature ${ }^{30}$. Interestingly, the storage pathway acts as a buffer, providing time for recycling processes to become more economical and ultimately 
diverting some modules from landfills (Figure 3a). This result suggests that encouraging recycling may be particularly critical where storage space is more limited (e.g., Japan).

Exploiting the ABM approach, we extend the traditional techno-economic analysis to include social factors such as conformity to peers and general attitude toward a specific behavior. Accounting for attitude is especially relevant for PV, because households and businesses may be inclined to environmental protection and thus recycling ${ }^{42,43}$. Our ABM can also be used to study interconnections and dynamics among different factors, as suggested by Lapko and colleagues ${ }^{38}$.

Our results confirm the importance of factors such as the learning effect, research and development to reduce recycling costs, and public engagement ${ }^{38}$. For manufacturers, recycling modules in a facility near the manufacturing line is a competitive advantage, because it makes manufacturing more resilient to supply restrictions and potentially facilitates recycling of manufacturing waste such as silicon kerf (Supplementary Figure 6). Recycling manufacturing waste is critical to improving circularity, because scrap materials are less contaminated and have compositions that are better known, compared with postconsumer materials ${ }^{44}$.

Our results show that a landfill ban, such as the one in Washington State ${ }^{31}$, could increase PV circularity substantially (Figure 1, scenario a). However, legislation alone may be insufficient. Current European legislation, for instance, encourages mass recycling but not necessarily high-quality multi-materials recycling ${ }^{26}$.

Our results finally show that high subsidies for a few years could be among the most efficient solutions for encouraging recycling. In contrast with Deng and colleagues, who found that landfill costs have the most potent effect, followed by recycling costs, we find that initial recycling costs have the most substantial effect, followed by landfill costs ${ }^{30}$. This difference occurs because our model is more refined, including social factors and dynamic modeling of the learning effect.

In future work, the ABM could be used to study other scenarios, such as the effect of public information campaigns on recycling rates. Moreover, although a design-related intervention is briefly presented (Figure 1e), more scenarios related to the design stage, such as modules with different backsheet materials ${ }^{45}$, could be explored. This novel approach combining ABM and ML could also be developed further to study the circularity of other technologies, such as consumer electronics, or to include environmental considerations.

\section{Methods}


Our ABM represents the main actors of the US PV sector that are involved in the transition to a more circular PV industry. Its objective is to find the techno-economic and social conditions that maximize materials circularity for EOL PV modules. The ABM's primary outputs are the mass volumes of modules reaching each EOL pathway (i.e., amounts that are reused, repaired, recycled, landfilled, or stored), the net revenue/cost for each $\mathrm{CE}$ actor, the value from recovered materials, and the number of years it takes to reach a specific objective. The overview, design concepts, and details (ODD) protocol is used to describe the $\mathrm{ABM}$ in this section ${ }^{46}$, followed by details on the ML approach used to build a metamodel of the $\mathrm{ABM}$ and the sensitivity analysis method.

\section{Overview}

The purpose of the ABM is to study implementation of CE strategies within the PV industry and identify the conditions maximizing circularity. Four types of agents are defined: PV owners, installers, recyclers, and manufacturers. Agents of a specific type behave similarly but have heterogeneous characteristics represented by probability distributions (e.g., recyclers may have different recycling costs). Agents are related to each other according to a social network representing the real-world relationships among the CE actors. In the simulation, a time step represents a year. The start of the simulation is $2020 ; 30$ time steps are chosen, because many installations will reach their EOL around $2050^{5}$.

At each time step, the ABM starts by modeling the cumulative amount of PV modules in use (i.e., the stocks) as well as the waste generated at their EOL. Then, agents make decisions about whether to comply with a particular CE strategy. The modeled CE strategies include repair, reuse (of a repaired/refurbished product), and recycle, and the two other options are landfill and store. Agent decisions are based on techno-economic factors-including technical feasibility, such as whether the modules can be repaired, and costs, such as landfill costs — and market factors (attitudes, social norms). The resulting volumes repaired, reused, recycled, landfilled, and stored change with each time step of the simulation. Supplementary Figure 1 presents an overview of the model.

\section{Design concept}

The ABM is designed in a modular fashion to ensure it can be used for different case studies; different types of agents may be defined and easily added to the model. Each agent type is defined as a Python module. In these modules, agent types are defined as a Python classes, and it follows that each agent is an instance of the class of its type. A Python model module contains all the user-defined inputs, activates the agents, and collects the outputs of the simulation. This modular structure is per the Mesa Python package $^{47}$. This package is used to facilitate the activation of the agents and set up batch runs of simulations. The NetworkX Python package is also used to build the social networks relating the agents ${ }^{48}$. 
Interactions between actors of the $\mathrm{CE}$ are captured at several levels in the $\mathrm{ABM}$ (that is, within agents of the same type and between agent types). First, because interactions between PV owners may influence their decisions regarding EOL management ${ }^{22,49,50}$, they are accounted for in the model. Second, information flows between agents of different types. For instance, PV owners have access to recyclers' recycling costs, and installers access the amount of PV modules being sold by PV owners. As another example, manufacturers know the amounts of materials being recovered by recyclers and compute the economic benefits of using those materials rather than virgin materials.

The model also contains several stochastic elements. First, the Watts Strogatz algorithm, which is widely used to build small-world networks, requires to rewire each edge of a regular graph with a certain probability ${ }^{48,51,52}$. Small-world networks are recognized as representing many real-world networks, including social networks ${ }^{51-54}$. Second, some of the agents' characteristics are drawn from probability distributions to model their variability (e.g., recycling or landfill costs may be different across the US). Finally, the system's overall behavior emerges from the agents' interactions and decisions during the simulation.

\section{Details}

At the beginning of the simulation, the network of agents is created. The stocks of PV modules from 2000 to 2020 are reported in the ABM and divided among PV owner agents. We chose stocks from 2000 to 2020 to account for existing installed capacity, assuming that, before 2000, the cumulative installed capacity was negligible. From there, several sub-models are used to represent various dynamics of the hypothetical circular PV sector.

\section{Environment}

The environment of the ABM is the US. Various interventions may be enacted in the environment to see their effects. For instance, scenarios studying the implementation of a tax or a ban may be modeled as part of the environment agents evolve within.

Moreover, agents' interactions are dependent on a social network that represents the real-world relationships between the PV industry actors. In contrast with aggregated models, the ABM enables modeling of different social network structures and provides insights into the social network role in the overall behavior of the system ${ }^{51}$. Different network structures are adapted to different real-world situations. For instance, a fully connected network is more adapted to describing small groups and tight communities. For socio-technical systems such as the power grid or cities, the small-world or scale-free networks are more realistic ${ }^{51,53}$. In the ABM, a small-world network is drawn using a rewiring probability and the average number of neighbors of 0.1 and 10, respectively. Those parameters are close to other works and real-world networks such as email communications ${ }^{51,55}$. 
Agents - PV owners

Owing to computational limitations, the number of PV owners was restricted to 1,000 agents. Although it limits the representativeness of the ABM, this number of agents enables capturing of network effects and the existing variability of PV owners (e.g., regarding landfill costs across the US or attitudes toward CE pathways). The PV owners make two decisions: 1) to purchase a new or a used product, and 2) to manage the EOL of their products.

Several processes are also occurring in the PV owners' module. First, the amount of product purchased each year is determined according to a piecewise function, following previous work ${ }^{5}$, and thus similar results for the projected installed capacity are obtained, although we only consider US c-Si PV modules. Values for the model's parameters can be found in Supplementary Table 1. Still following the literature, the efficiency growth of PV modules is accounted for with an exponential function ${ }^{5}$. Next, a Weibull function is used to generate the amount of PV modules of agent $i$ reaching EOL at time $t, E L P V_{i}^{t}$ (Equation 1).

$$
E L P V_{i}^{t}=\sum_{t} R P A_{i}^{t} \times\left(1-e^{-(t / T)^{\alpha}}\right)
$$

In the equation, $T$ is the average lifetime of PV modules, $\alpha$ the shape factor (controlling the typical $\mathrm{S}$ shape of the Weibull curve), and $R P A_{i}^{t}$ is the remaining amount of PV modules installed by agent $i$ at time step $t$. The Weibull function is appropriate to model PV waste generation ${ }^{5}$.

The $\mathrm{TPB}^{56}$ is used to model the PV owners' decisions to purchase used or new modules and the EOL management of those modules. The TPB stipulates that human behaviors are influenced by: 1) the attitude $A$ individuals hold toward the behavior (i.e., how the behavior is perceived as favorable or unfavorable), 2) the subjective norm $S N$, which refers to the perceived social pressure to perform or not perform the behavior, and 3) the perceived behavioral control $P B C$, which relates to the perceived ease or difficulty of performing the behavior (Equation 2).

$$
B I=w_{A} A+w_{S N} S N+w_{P B C} P B C
$$

In the equation, $B I$ is the intention to perform the behavior, and $w_{A}, w_{S N}$, and $w_{P B C}$ are the weights of each factor in the overall decision. The TPB is often used in ABMs of socio-technical systems because it explains the process of individual decision making straightforwardly ${ }^{21,24,57}$ and has been applied in many waste-management $\mathrm{ABMs}^{21,22,24}$. The theory explains consumers' decisions ${ }^{58,59}$ as well as decisions within companies $^{13,60-62}$. In our ABM, a score is attributed to each EOL pathway according to the TPB. The attitude level of each agent regarding CE pathways (repairing, reusing, and recycling) is normally distributed between 0 (negative attitude) and 1 (positive attitude). The attitude level toward linear 
pathways (landfilling, storing) is simply assumed to be one minus the attitude held for CE pathways. Although this distribution of agents is rather simple when compared to the literature ${ }^{21}$, it is deemed sufficient for this exploratory analysis. Because the parameters of the truncated normal distribution were unknown, they were calibrated. Thus, an iterative process was undertaken to find the values that reproduce low recycling ${ }^{3,8}$ and reuse ${ }^{63}$ rates as they represent today's situation. The second element of the $\mathrm{TPB}$, the subjective norm $S N_{i p}^{t}$ of agent $i$ and pathway $p$ at $t$, is defined as per Equation 3 .

$$
S N_{i p}^{t}=\sum_{n} \frac{P a t h_{n p}^{t}}{N}
$$

With $P a t h_{n p}^{t}$ being one if agent $i$ 's neighbor $n$ has selected the path $p$ and zero otherwise, and $N$ being the total number of neighbors of agent $i$. Thus, the subjective norm takes values between zero (no peer pressure) and one (maximum peer pressure). While in the ABM neighbors designate nodes that share an edge in the small-world network, they may represent various relationships among PV owners in the real world (e.g., friends, family, coworkers, and actual neighbors). The third element of the TPB, the perceived behavioral control $P B C_{i p}^{t}$ of agent $i$ and pathway $p$ at $t$, is given by Equation 4:

$$
P B C_{i p}^{t}=-\max \left(0 ; \frac{\operatorname{Cost}_{i p}^{t}}{\left|\max \left\{\operatorname{Cost}_{i p}^{t} \forall p\right\}\right|}\right)
$$

Where $\operatorname{Cost}_{i p}^{t}$ is the cost of choosing the pathway $p$ at $t$ for agent $i$. Finally, the behavioral intention $B I_{i p}^{t}$ of agent $i$ for pathway $p$ at $t$ is defined by Equation 5

$$
B I_{i p}^{t}=w_{A} A_{i p}^{t}+w_{S N} S N_{i p}^{t}+w_{P B C} P B C_{i p}^{t}
$$

In Equation 5, the values for the coefficients $w_{A}, w_{S N}$, and $w_{P B C}$ are taken from an existing meta-analysis on factors affecting EOL management decisions ${ }^{50}$. Even though we use a meta-analysis, the coefficients' values are uncertain and, thus, could alternatively be calibrated. However, the lack of empirical data prevents us from conducting such extensive calibration. The agent then selects the EOL pathway with the highest score (and the amount of EOL modules $E L P V_{i}^{t}$ is recorded as following the selected pathway for further use by other agents and the output metrics).

The TPB is also used to model the purchase decision, similar to how the EOL decision is modeled. Two options are represented in this ABM, the purchase of a new or a used module (see Supplementary Figure 14). Another meta-analysis is used to determine the TPB coefficient values for the purchase decision ${ }^{58}$. The TPB may be interpreted in terms of material efficiency potentials. If one defines $w_{A}$ and $w_{S N}$ to be 0 , the techno-economic potentials of the recycling, repairing, and reusing CE strategies may be studied on their own. Otherwise, the social factors of the model (the subjective norm and attitude) may be added, enabling study of the achievable (or market) potential of material efficiency ${ }^{15}$. 


\section{Agents - Installers}

Installers are the second type of agent. In the PV sector, installers may be in charge of collecting EOL PV modules and eventually sorting them before selling them on the secondary market ${ }^{64}$. They may also repair failed modules if PV owners opt for that EOL pathway. If there is insufficient demand for used modules or if they are too damaged or cost too much to be repaired (Equations 6-7), installers send them to a recycler or landfill, or they store them until another decision is made depending on the cheapest decision at the time of the simulation (using Equation 4). It is assumed in this model that handling used PV modules always bears the same repair costs (whether modules are repaired directly for PV owners or sold as used products) regardless of possible damage to the EOL modules.

$$
\begin{gathered}
V_{j}^{t}=\frac{R R \times\left(\sum_{i} V_{i}^{t}+\sum_{k} V_{k}^{t}\right)}{\sum j} \text { for } i \text { and } k \text { such that } R C_{i}^{t} \leq R P_{j}^{t} \text { and } R C_{k}^{t} \leq R P_{j}^{t} \\
R A_{j}^{t}=\left\{\begin{array}{l}
V_{j}^{t} \text { if } \sum_{j} V_{j}^{t} \leq \sum_{i} D U_{i}^{t} \text { for } i \text { such as } P U_{i}^{t}=1 \\
0 \text { otherwise }
\end{array}\right.
\end{gathered}
$$

In the equations, $V_{j}^{t}$ is the volume of modules available for sale on the secondary market by installer $j$. Next, $R R$ is the module repair rate, $V_{i}^{t}$ and $V_{k}^{t}$ are the volume of modules flowing from the PV owner $i$ and recycler $k$ at time $t$, respectively, $R C_{i}^{t}$ and $R C_{k}^{t}$ are the repair costs of modules from PV owner $i$ and recycler $k$ at time $t$, respectively, and $R P_{j}^{t}$ is the price at which agent $j$ is selling the used modules on the secondary market at time $t$. Finally, $R A_{j}^{t}$ is the amount of used modules handled by installer $j$ that is sold on the secondary market at time $t$; it depends on the demand for used modules from PV owners $\left(\sum_{i} D U_{i}^{t}\right)$. In the equation, $P U_{i}^{t}$ is a boolean being one when the PV owner $i$ has decided to purchase a used module at time $t$ and zero otherwise. Installers also improve their repair processes owing to the learning effect, thus decreasing repair costs. The learning effect can be characterized by several mechanisms, such as technology advancement, increased labor productivity, economies of scale, and improved material and energy efficiency ${ }^{28}$. As the volume of EOL PV modules dealt by an installer increases, at least three of these mechanisms may apply: increased labor productivity, economies of scale, and energy efficiency. In the $\mathrm{ABM}$, the learning effect is modeled as a function of the repaired volume, following the literature ${ }^{28}$.

Agents - Recyclers

Recycler agents are similar to installers in two ways. First, they may take on the responsibility of sorting EOL PV modules that can be sold on secondary markets (with those modules then flowing to installers); this behavior was assessed via interviews with a US recycler ${ }^{65}$. Second, recyclers improve their recycling processes in the model, simulating the learning effect. Another recycler role is to recover materials from EOL PV modules. In the ABM, this is simply modeled from the material recovery rates of a given 
recycling process (e.g., simple mechanical processes or the FRELP process ${ }^{26}$ ), the fractions of materials that constitute PV modules, and the volume of modules being recycled. In the ABM, PV owners pay a fee to recycle EOL PV modules, while manufacturers buy recycled materials at market prices. With current US recycling processes, revenue from recovered materials is insufficient to cover recycling costs ${ }^{26}$.

Agents - Manufacturers

Manufacturer agents purchase recovered materials from recyclers. The avoided costs from using recovered rather than virgin materials can be computed within the model based on their respective values. For instance, the price of aluminum scrap is often about $60 \%$ of the price of virgin aluminum ${ }^{66}$, which brings profits for manufacturers that use aluminum.

\section{Validation}

We applied four validation techniques to ensure the quality of the results produced by the model: theory validation, data validation, model output validation, and face validation ${ }^{67}$. First, regarding theory validation, only empirically validated models were used (e.g., TPB). Next, for the baseline scenario, empirical data were mostly used; when parameters were unknown, they were calibrated ${ }^{3,5,8,63}$. Then, the cumulative installed capacity and the mass of EOL PV modules generated during the 2020 to 2050 period were validated with the literature ${ }^{5}$ (Supplementary Figure 5). Finally, the results of the ABM went through an internal revision process with ABM and PV experts to ensure the model was behaving in a meaningful way, and extreme scenarios were also studied (see Supplementary Table 6).

\section{Machine-learning metamodel and sensitivity analysis}

The combination of ABM and ML has recently gained attention owing to the complementarity of the two approaches ${ }^{68}$. These methods can be combined in two ways: ML can generate agent behavioral rules from data $^{35}$, and an ABM can be explored in depth (i.e., varying the ABM inputs to examine a wide range of possible outputs) by building a ML metamodel (i.e., a model of a model) that avoids computationally intensive simulations and saves time ${ }^{69}$. Because of the exploratory nature of this work, we use the second approach in this study. Following Vadhati and colleagues, we built a ML metamodel of the ABM described above ${ }^{69}$. Using the Scikit-learn Python library ${ }^{70}$, we constructed different ML models using different combinations of hyperparameters. In our study, all features (input data) and output data are known in the dataset generated by the ABM; thus, supervised ML is used.

In this study, the training dataset is generated with the ABM. To produce the dataset that best represents the behavior space of our model while limiting the required number of simulations, we use a quasiMonte-Carlo approach. First, the range of each parameter to vary in the quasi-Monte-Carlo simulations is defined. For some parameters, it is merely their minimum and maximum possible values (e.g., for ratios). 
For parameters without theoretical bounds, realistic ranges are defined according to the literature. For landfill costs, for instance, the minimum value is set to zero, while the maximum value is set to twice the average value of the baseline scenario; it seems unrealistic that landfill costs could be higher than that based on current trends ${ }^{27}$. A similar logic is applied to other parameters (Supplementary Table 5). Next, the method from Saltelli and colleagues is used to generate the Sobol sequences of parameter value combinations $^{71}$. Sobol sequences aim to approximate the model's behavior within the parameter space by attempting to cover as much of the parameter space as possible as quickly (with the fewest samples) as possible. This is one of the highest-performing methods (e.g., compared with the Latin hypercube design) regarding the quality of results obtained as a function of computational time, and it is often used to build metamodels $\mathrm{s}^{72,73}$. Thus, using the SALib Python library ${ }^{74}, 2,800$ parameter value combinations are generated, to which we add the baseline parameter value combination as well as variants of the baseline varying each parameter to its lower and upper bound (to include extreme cases in our dataset). In total, 2,810 parameter value combinations are run a total of 6 times (to account for the stochasticity of the model), amounting to 16,860 simulations.

Next, we iterate 10-fold cross-validation, varying the ML algorithm, its hyperparameters, and the output metric considered in the dataset. We keep the multilayer perceptron regressor algorithm, which yields a good compromise between computation time and a high coefficient of determination in all output metrics (Supplementary Table 7). Once trained, the metamodel is used to predict the outputs of parameter value combinations not run with the ABM. The SALib library is finally used to conduct a variance-based (Sobol) sensitivity analysis and thus measure the uncertainty of model outputs that can be accounted for by changes in model inputs. We use the Sobol method because of its ability to evaluate interaction effects and the low risk that dependencies exist between the parameters of our ABM. Moreover, we compare results from the variance-based sensitivity analysis with results from a moment-independent sensitivity analysis to confirm rankings of parameters (Supplementary Table 3). Because of the use of the ML metamodel, results from Figures 3b, 5, and 6, Supplementary Tables 3-5, and Supplementary Figures 913 are approximations of the ABM's results.

\section{Data availability}

The authors declare that the data supporting the findings of this study are available within the paper and its supplementary information files.

\section{Code availability}


The source code for the model developed in this study can be accessed on:

https://github.com/NREL/ABSiCE

\section{Acknowledgments}

This work was authored in part by the National Renewable Energy Laboratory, operated by Alliance for Sustainable Energy, LLC, for the U.S. Department of Energy (DOE) under Contract No. DE-AC3608GO28308. Funding provided by the Advanced Manufacturing Office and the Office of Strategic Program. The views expressed in the article do not necessarily represent the views of the DOE or the U.S. Government. The U.S. Government retains and the publisher, by accepting the article for publication, acknowledges that the U.S. Government retains a nonexclusive, paid-up, irrevocable, worldwide license to publish or reproduce the published form of this work, or allow others to do so, for U.S. Government purposes. We would also like to thank Jarett Zuboy for its insightful edits, Robin Burton and Liam Watts for their help with data collection, Silvana Ayala, Ashok Sekar, Dwarak Ravikumar, Alexandre Labelle, Andreas Wade, Parikhit Sinha for their helpful comments on an earlier draft of the manuscript, as well as the National Renewable Energy Laboratory's dGen model team and Reliability and System Performance Group for their helpful comments on early versions of the model.

\section{Declarations of interest: None}




\section{References}

1 Department of the Interior. Final List of Critical Minerals 2018,

<https://www.federalregister.gov/documents/2018/05/18/2018-10667/final-list-of-critical-minerals-2018> (2018).

2 Trube, J. et al. International technology roadmap for photovoltaic (ITRPV). VDMA photovoltaic

equipement (2018).

3 Farrell, C. C. et al. Technical challenges and opportunities in realising a circular economy for waste photovoltaic modules. Renewable and Sustainable Energy Reviews 128, 109911, doi:https://doi.org/10.1016/j.rser.2020.109911 (2020).

Sovacool, B. K. et al. Sustainable minerals and metals for a low-carbon future. Science 367, 30-33, doi:10.1126/science.aaz6003 (2020).

IRENA \& IEA. End-of-Life Management: Solar Photovoltaic Panels. Report No. IEA-PVPS Task 12. Report \#T12-06:2016, (2016).

6 Stahel, W. R. The circular economy. Nature 531, 435-438, doi:10.1038/531435a (2016).

Linder, M., Sarasini, S. \& van Loon, P. A Metric for Quantifying Product-Level Circularity. Journal of Industrial Ecology 21, 545-558, doi:10.1111/jiec.12552 (2017).

Ardente, F., Latunussa, C. E. L. \& Blengini, G. A. Resource efficient recovery of critical and precious metals from waste silicon PV panel recycling. Waste Management 91, 156-167, doi:https://doi.org/10.1016/j.wasman.2019.04.059 (2019).

Stolz, P., Frischknecht, R., Wambach, K., Sinha, P. \& Heath, G. Life cycle assessment of current photovoltaic module recycling. IEA PVPS Task 12, International Energy Agency Power Systems Programme, Report IEA-PVPS T12 13, 2018 (2017).

Harms, R. \& Linton, J. D. Willingness to Pay for Eco-Certified Refurbished Products: The Effects of Environmental Attitudes and Knowledge. Journal of Industrial Ecology 20, 893-904, doi:10.1111/jiec.12301 (2016).

Salim, H. K., Stewart, R. A., Sahin, O. \& Dudley, M. Drivers, barriers and enablers to end-of-life management of solar photovoltaic and battery energy storage systems: A systematic literature review. Journal of Cleaner Production 211, 537-554, doi:https://doi.org/10.1016/j.jclepro.2018.11.229 (2019). Moraga, G. et al. Circular economy indicators: What do they measure? Resources, Conservation and Recycling 146, 452-461, doi:https://doi.org/10.1016/j.resconrec.2019.03.045 (2019).

Khan, O. et al. Assessing the determinants of intentions and behaviors of organizations towards a circular economy for plastics. Resources, Conservation and Recycling 163, 105069, doi:https://doi.org/10.1016/j.resconrec.2020.105069 (2020).

14 Sovacool, B. K. \& Griffiths, S. Culture and low-carbon energy transitions. Nature Sustainability 3, 685693, doi:10.1038/s41893-020-0519-4 (2020).

Nadel, S., Shipley, A. \& Elliott, R. N. in Proceedings of the 2004 ACEEE Summer Study on Energy Efficiency in Buildings. 8.215-218.226 (Citeseer).

Walzberg, J. et al. Do We Need a New Sustainability Assessment Method for the Circular Economy? A Critical Literature Review. Frontiers in Sustainability 1, doi:10.3389/frsus.2020.620047 (2021).

Calisto Friant, M., Vermeulen, W. J. V. \& Salomone, R. A typology of circular economy discourses: Navigating the diverse visions of a contested paradigm. Resources, Conservation and Recycling 161, 104917, doi:https://doi.org/10.1016/j.resconrec.2020.104917 (2020).

Thaler, R. H. \& Sunstein, C. R. Nudge : improving decisions about health, wealth, and happiness. (Yale University Press, 2008).

19 Hansen, P., Liu, X. \& Morrison, G. M. Agent-based modelling and socio-technical energy transitions: A systematic literature review. Energy Research \& Social Science 49, 41-52, doi:https://doi.org/10.1016/j.erss.2018.10.021 (2019).

Walzberg, J., Dandres, T., Merveille, N., Cheriet, M. \& Samson, R. Assessing behavioural change with agent-based life cycle assessment: Application to smart homes. Renewable and Sustainable Energy Reviews 111, 365-376, doi:https://doi.org/10.1016/j.rser.2019.05.038 (2019). doi:https://doi.org/10.1016/j.jclepro.2018.03.261 (2018). 

77-97 (Springer International Publishing, 2017).

Heath, G. A. et al. Research and development priorities for silicon photovoltaic module recycling to support a circular economy. Nature Energy, doi:10.1038/s41560-020-0645-2 (2020). (2018). technologies. Resources, Conservation and Recycling 150, 104432, doi:https://doi.org/10.1016/j.resconrec.2019.104432 (2019).

Deng, R., Chang, N. L., Ouyang, Z. \& Chong, C. M. A techno-economic review of silicon photovoltaic module recycling. Renewable and Sustainable Energy Reviews 109, 532-550, doi:https://doi.org/10.1016/j.rser.2019.04.020 (2019).

31 S.B. 5939, t. L., 3rd Spec. Sess. (Wa)). 2017.

32 H.B. 125, L., 439th Sess. (Md. 2019).

33 Choi, J.-K. \& Fthenakis, V. Crystalline silicon photovoltaic recycling planning: macro and micro perspectives. Journal of Cleaner Production 66, 443-449, doi:https://doi.org/10.1016/j.jclepro.2013.11.022 (2014).

34 Schmid, M. Used Solar Panels Change the Game in the 2020s as Used Cars Did in the 1930s, <https://resources.energybin.com> (2020).

35 Zhang, H., Vorobeychik, Y., Letchford, J. \& Lakkaraju, K. Data-driven agent-based modeling, with application to rooftop solar adoption. Autonomous Agents and Multi-Agent Systems 30, 1023-1049, doi:10.1007/s10458-016-9326-8 (2016).

Yu, J., Wang, Z., Majumdar, A. \& Rajagopal, R. DeepSolar: A Machine Learning Framework to Efficiently Construct a Solar Deployment Database in the United States. Joule 2, 2605-2617, doi:10.1016/j.joule.2018.11.021 (2018).

Kwasnik, T., Sigrin, B. O. \& Bielen, D. A. Quantifying Resolution Implications for Agent-based Distributed Energy Resource Customer Adoption Models. (United States, 2019).

38 Lapko, Y., Trianni, A., Nuur, C. \& Masi, D. In Pursuit of Closed-Loop Supply Chains for Critical Materials: An Exploratory Study in the Green Energy Sector. Journal of Industrial Ecology 23, 182-196, doi:10.1111/jiec.12741 (2019).

Tao, M. et al. Major challenges and opportunities in silicon solar module recycling. Progress in Photovoltaics: Research and Applications n/a, doi:10.1002/pip.3316.

Skene, K. R. Circles, spirals, pyramids and cubes: why the circular economy cannot work. Sustainability Science 13, 479-492, doi:10.1007/s11625-017-0443-3 (2018).

Morseletto, P. Targets for a circular economy. Resources, Conservation and Recycling 153, 104553, doi:https://doi.org/10.1016/i.resconrec.2019.104553 (2020).

Braito, M., Flint, C., Muhar, A., Penker, M. \& Vogel, S. Individual and collective socio-psychological patterns of photovoltaic investment under diverging policy regimes of Austria and Italy. Energy Policy 109, 141-153, doi:https://doi.org/10.1016/j.enpol.2017.06.063 (2017).

Chrun, E., Dolšak, N. \& Prakash, A. Corporate Environmentalism: Motivations and Mechanisms. Annual Review of Environment and Resources 41, 341-362, doi:10.1146/annurev-environ-110615-090105 (2016).

Ragaert, K., Hubo, S., Delva, L., Veelaert, L. \& Du Bois, E. Upcycling of contaminated post-industrial polypropylene waste: A design from recycling case study. Polymer Engineering \& Science 58, 528-534, doi:10.1002/pen.24764 (2018).

Norgren, A., Carpenter, A. \& Heath, G. Design for Recycling Principles Applicable to Selected Clean Energy Technologies: Crystalline-Silicon Photovoltaic Modules, Electric Vehicle Batteries, and Wind Turbine Blades. Journal of Sustainable Metallurgy, doi:10.1007/s40831-020-00313-3 (2020). Modelling 198, 115-126, doi:http://dx.doi.org/10.1016/j.ecolmodel.2006.04.023 (2006). 47 Masad, D. \& Kazil, J. in 14th PYTHON in Science Conference. 53-60. NetworkX. (Los Alamos National Lab.(LANL), Los Alamos, NM (United States), 2008). 
49 Meng, X., Wen, Z. \& Qian, Y. Multi-agent based simulation for household solid waste recycling behavior. Resources, Conservation and Recycling 128, 535-545, doi:https://doi.org/10.1016/j.resconrec.2016.09.033 (2018).

50 Geiger, J. L., Steg, L., van der Werff, E. \& Ünal, A. B. A meta-analysis of factors related to recycling. Journal of Environmental Psychology 64, 78-97, doi:https://doi.org/10.1016/j.jenvp.2019.05.004 (2019).

Byrka, K., Jẹdrzejewski, A., Sznajd-Weron, K. \& Weron, R. Difficulty is critical: The importance of social factors in modeling diffusion of green products and practices. Renewable and Sustainable Energy Reviews 62, 723-735, doi:http://dx.doi.org/10.1016/j.rser.2016.04.063 (2016).

Watts, D. J. \& Strogatz, S. H. Collective dynamics of 'small-world'networks. nature 393, 440-442 (1998).

53 Telesford, Q. K., Joyce, K. E., Hayasaka, S., Burdette, J. H. \& Laurienti, P. J. The Ubiquity of Small-World Networks. Brain Connectivity 1, 367-375, doi:10.1089/brain.2011.0038 (2011).

Humphries, M. D., Gurney, K. \& Prescott, T. J. The brainstem reticular formation is a small-world, not scale-free, network. Proceedings of the Royal Society B: Biological Sciences 273, 503-511, doi:10.1098/rspb.2005.3354 (2006).

Jalili, M. Social power and opinion formation in complex networks. Physica A: Statistical Mechanics and its Applications 392, 959-966, doi:https://doi.org/10.1016/j.physa.2012.10.013 (2013).

Ajzen, I. The Theory of Planned Behavior. Organizational Behavior and Human Decision Processes 50, 179-211 (1991).

57 Muelder, H. \& Filatova, T. One Theory - Many Formalizations: Testing Different Code Implementations of the Theory of Planned Behaviour in Energy Agent-Based Models. Journal of Artificial Societies and Social Simulation 21, 5, doi:10.18564/jasss.3855 (2018).

Singhal, D., Jena, S. K. \& Tripathy, S. Factors influencing the purchase intention of consumers towards remanufactured products: a systematic review and meta-analysis. International Journal of Production Research 57, 7289-7299, doi:10.1080/00207543.2019.1598590 (2019).

Morren, M. \& Grinstein, A. Explaining environmental behavior across borders: A meta-analysis. Journal of Environmental Psychology 47, 91-106, doi:https://doi.org/10.1016/j.jenvp.2016.05.003 (2016). Journal of Cleaner Production 161, 452-465, doi:https://doi.org/10.1016/j.jclepro.2017.05.128 (2017). Arslan, M. \& Şar, S. Examination of environmentally friendly "green" logistics behavior of managers in the pharmaceutical sector using the Theory of Planned Behavior. Research in Social and Administrative Pharmacy 14, 1007-1014, doi:https://doi.org/10.1016/j.sapharm.2017.12.002 (2018).

Raab, C., Baloglu, S. \& Chen, Y.-S. Restaurant Managers' Adoption of Sustainable Practices: An Application of Institutional Theory and Theory of Planned Behavior. Journal of Foodservice Business Research 21, 154-171, doi:10.1080/15378020.2017.1364591 (2018).

Seyring, N. et al. Study on WEEE recovery targets, preparation for re-use targets and on the method for calculation of the recovery targets. EU Commission (2015).

64 Schmid, M. A. 3 Economic Drivers Make Viable Today's Solar Secondary Market, <https://resources.energybin.com/solar-resources/economic-drivers-make-viable-solar-secondary-market>

$$
\text { (2020). }
$$

66 USGS. 2017 Minerals Yearbook - Aluminum. 16 (2020).

67 Sopha, B. M., Klöckner, C. A. \& Febrianti, D. Using agent-based modeling to explore policy options supporting adoption of natural gas vehicles in Indonesia. Journal of Environmental Psychology 52, 149165, doi:https://doi.org/10.1016/j.jenvp.2016.06.002 (2017).

68 Rand, W. in Social - Behavioral Modeling for Complex Systems 337-357 (2019).

R. Vahdati, A., Weissmann, J. D., Timmermann, A., Ponce de León, M. S. \& Zollikofer, C. P. E. Drivers of Late Pleistocene human survival and dispersal: an agent-based modeling and machine learning approach. Quaternary Science Reviews 221, 105867, doi:https://doi.org/10.1016/j.quascirev.2019.105867 (2019). 2825-2830 (2011).

71 Saltelli, A. Making best use of model evaluations to compute sensitivity indices. Computer Physics Communications 145, 280-297, doi:https://doi.org/10.1016/S0010-4655(02)00280-1 (2002).

72 Kucherenko, S., Albrecht, D. \& Saltelli, A. Exploring multi-dimensional spaces: A comparison of Latin hypercube and quasi Monte Carlo sampling techniques. arXiv preprint arXiv:1505.02350 (2015). 
74 Herman, J. \& Usher, W. SALib: an open-source Python library for sensitivity analysis. Journal of Open Source Software 2, 97 (2017). 


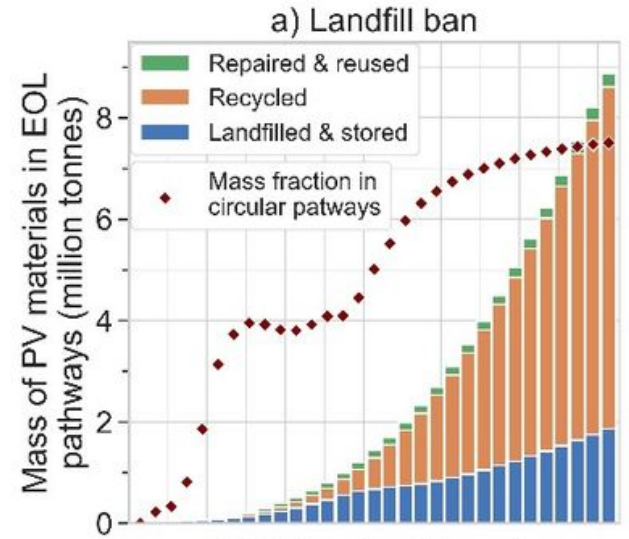

d) Higher landfill costs (\$2.75/module)

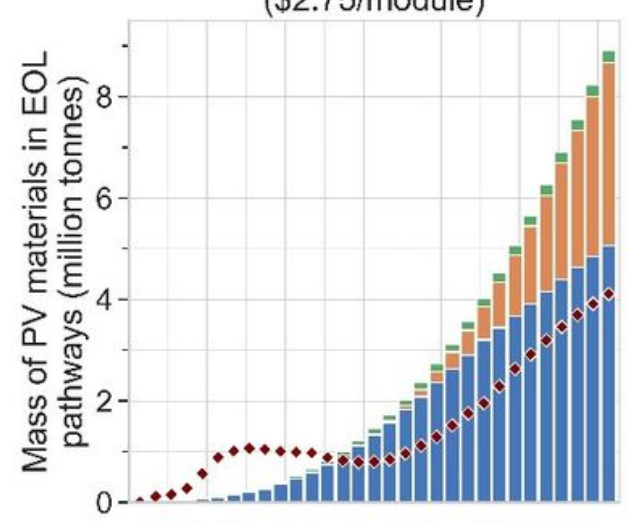

g) Reuse warranties (equal new/used attitude)

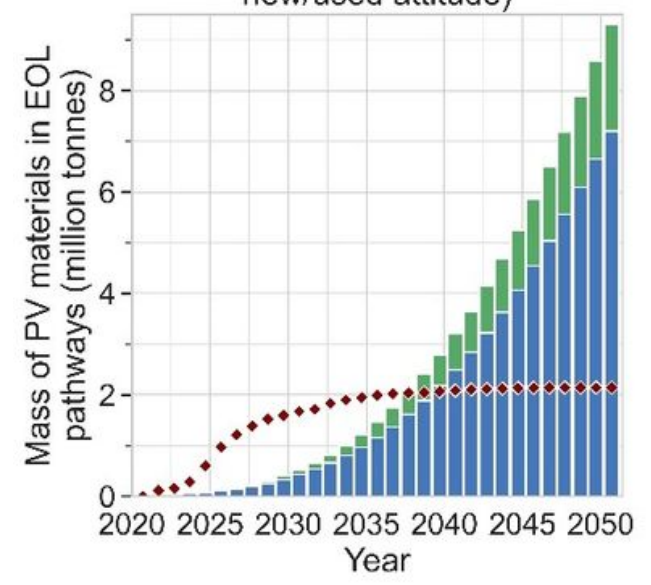

b) High material recovery $(96 \%)$

\& $\$ 18 /$ module recycling costs

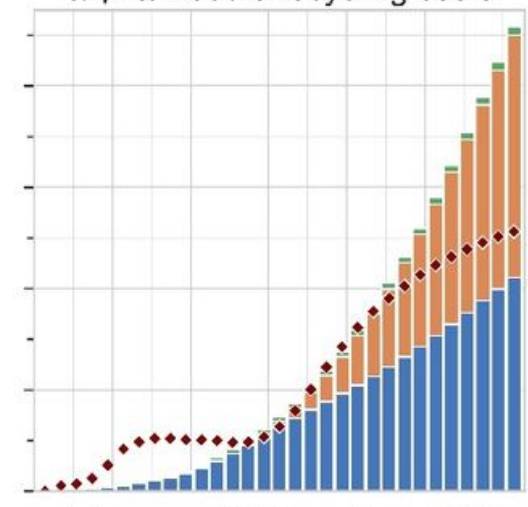

e) Improved lifetime (from 30 to 60 years in 2050)

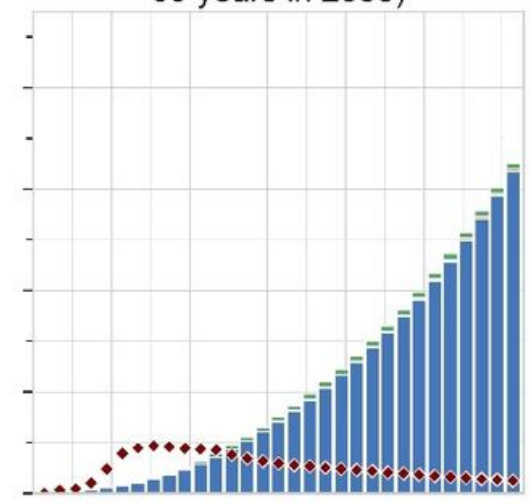

h) Seeding reuse $(5 \%$ of population per year)

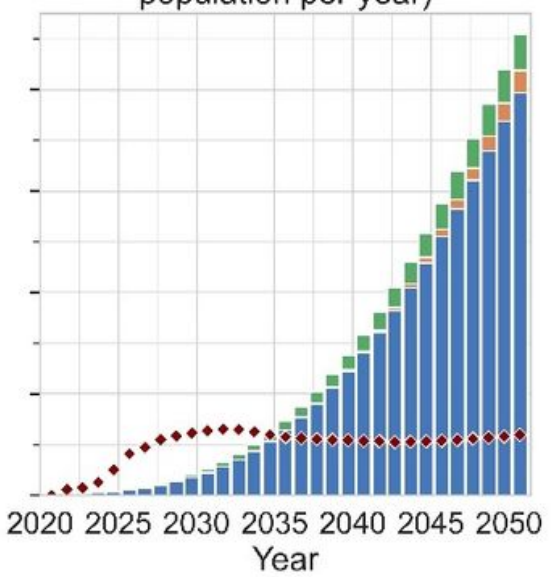

c) Lower recycling costs ( $\$ 18 /$ module)

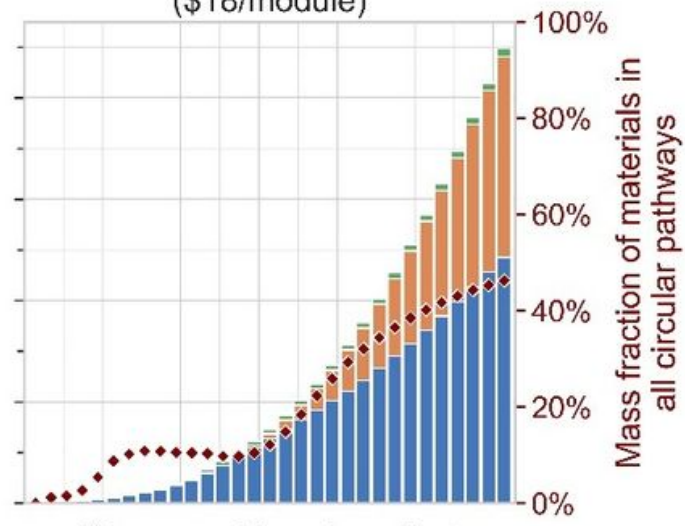

f) Improved learning effect (learning parameter $=0.6$ )

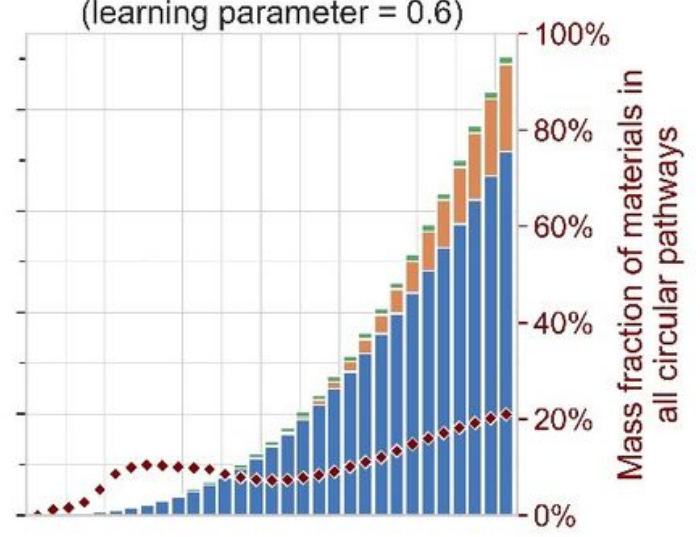

i) Baseline

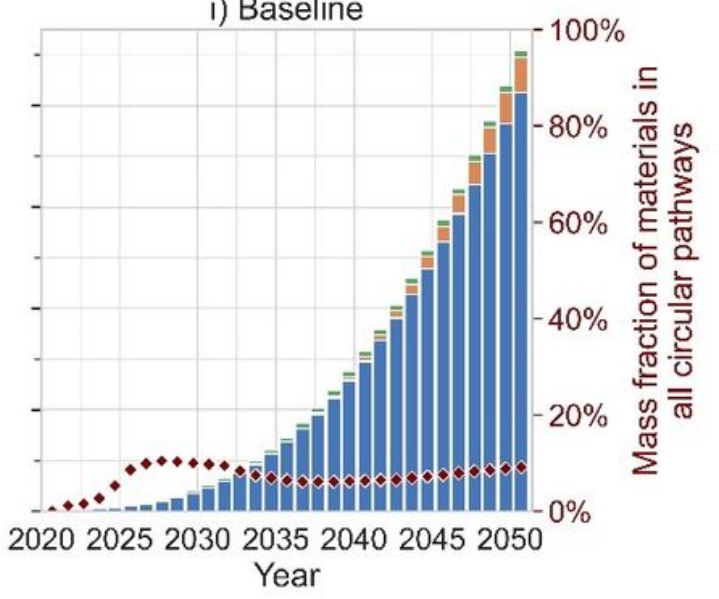

\section{Figure 1}

Various interventions could improve material circularity in the PV sector. Some interventions, including improved warranties $(\mathrm{g})$ and seeding used modules $(\mathrm{h})$, particularly boost module repair and reuse. Other interventions, such as lower initial recycling costs (c) and higher landfill costs (d), boost recycling. Reuse of EOL PV modules is limited by customer willingness to purchase used modules, which explains the circularity rate decline around 2035 in some scenarios, as EOL PV modules move from the reuse pathway 
to the landfill pathway. Although the simulations start in 2020, the generation of EOL PV modules is assumed to start from modules installed in 2000.

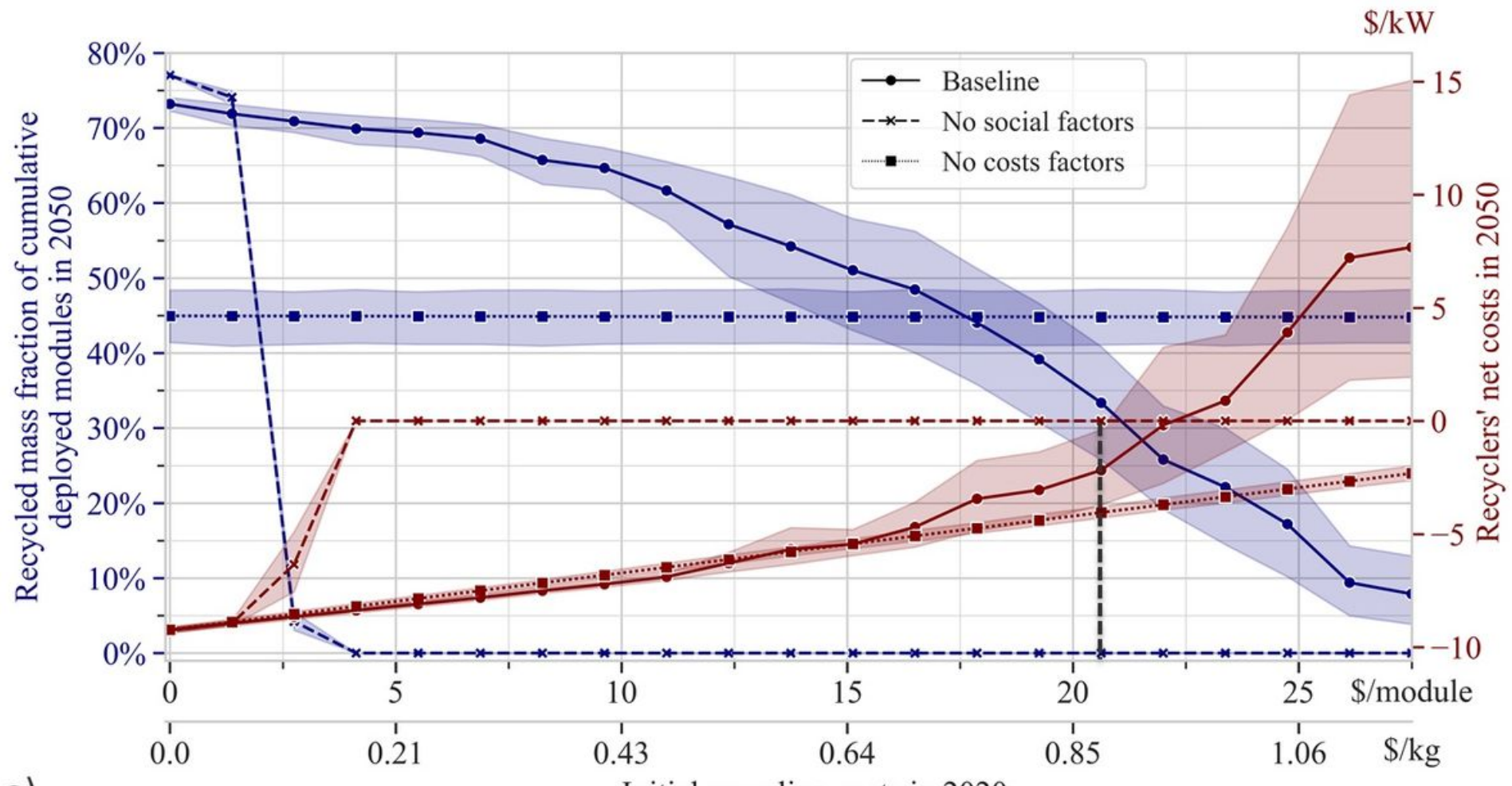
a)
Initial recycling costs in 2020
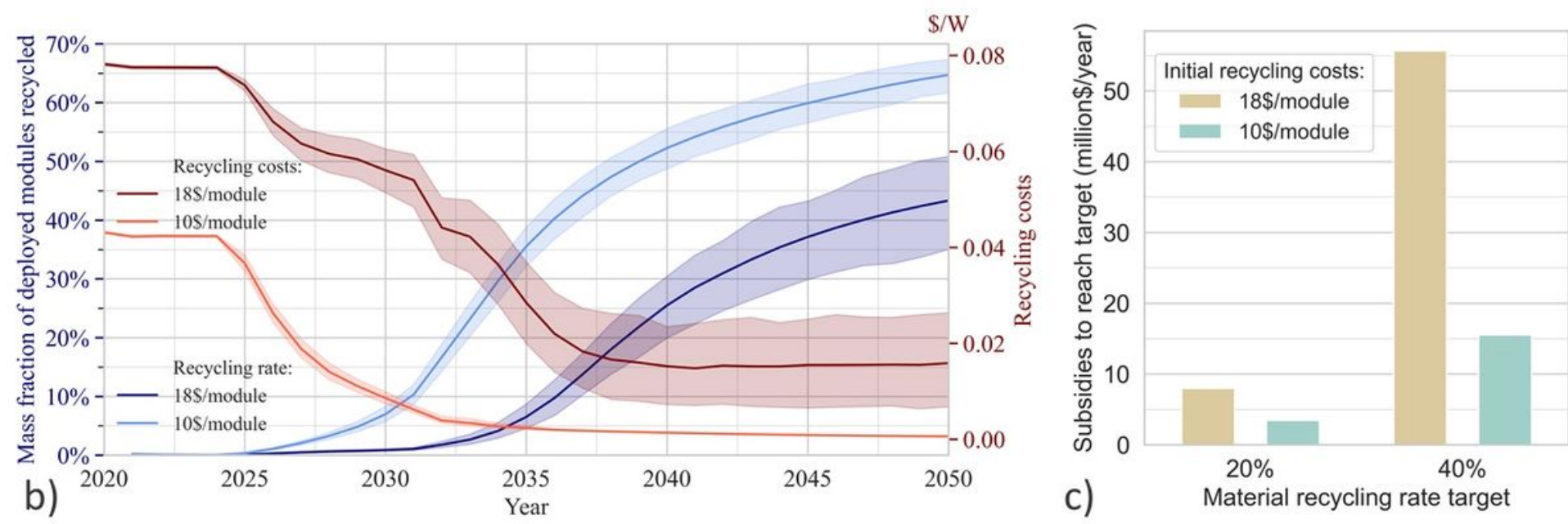

\section{Figure 2}

a) In the baseline scenario, the volume of materials recycled (cumulative total in 2050) quickly increases with falling initial recycling costs before reaching a plateau. Not accounting for economic factors (costs of recycling for PV owners) and social factors (attitude and peer influence) misrepresents the effect of lower initial recycling costs on the volume of materials recycled. Recycling is profitable (provides negative net costs, i.e., recycling costs minus value of recovered materials) by 2050 for initial recycling costs of $\$ 21 /$ module or less (black dashed line). Shaded areas represent $95 \%$ confidence intervals. b) Recycling costs decrease with the amount of PV modules being recycled. Shaded areas represent $95 \%$ confidence intervals. See Supplementary Figure 7 for a y-axis in $\$ / \mathbf{k g}$. c) High initial subsidies (initial recycling costs 
of $\$ 10 /$ module) boost recycling and help recyclers be profitable (due to the learning effect) more quickly than low subsidies (initial recycling costs of $\$ 18 /$ module), resulting in lower overall costs for the subsidy provider (\$16 million/year instead of $\$ 56$ million/year to reach a $40 \%$ recycling rate).
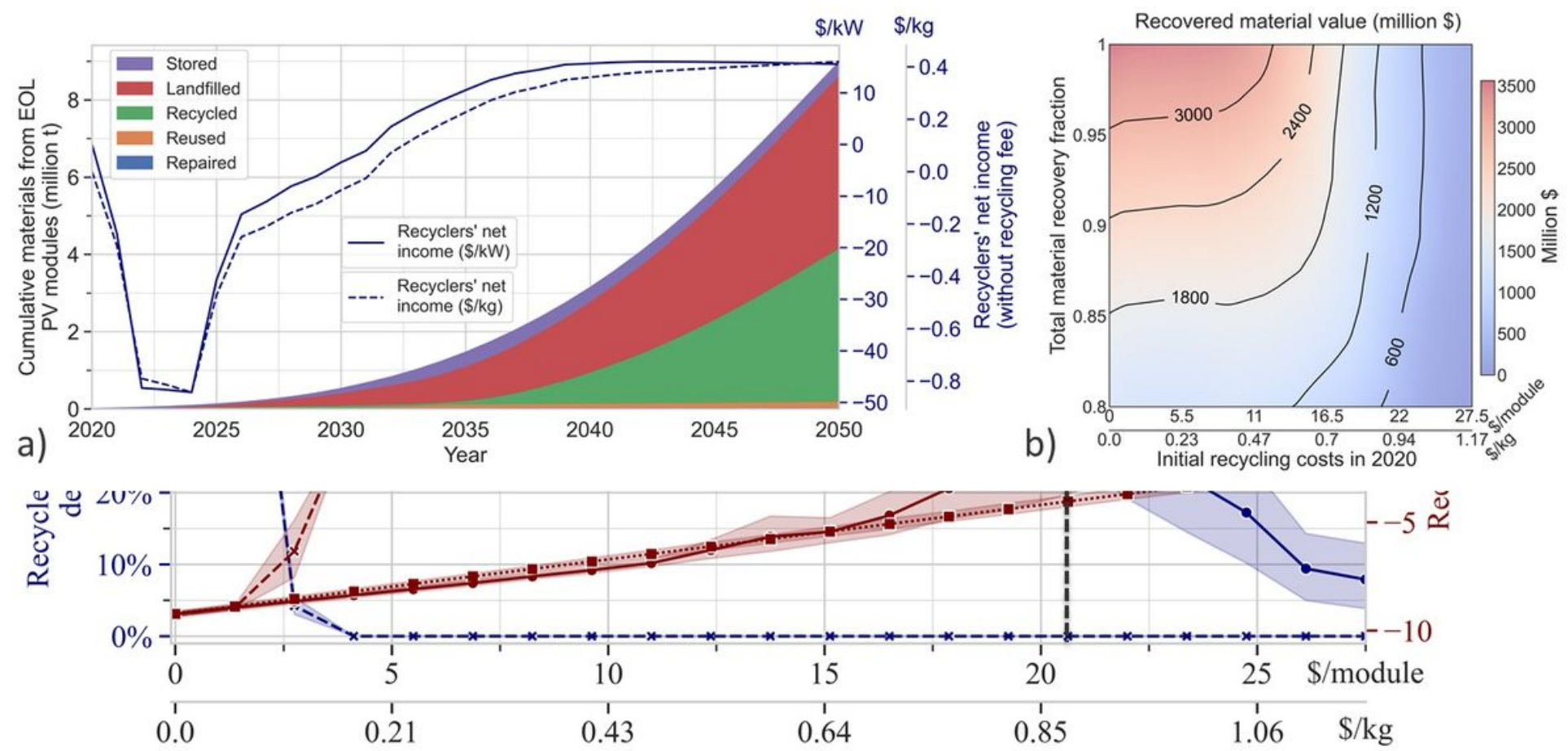
a)
Initial recycling costs in 2020
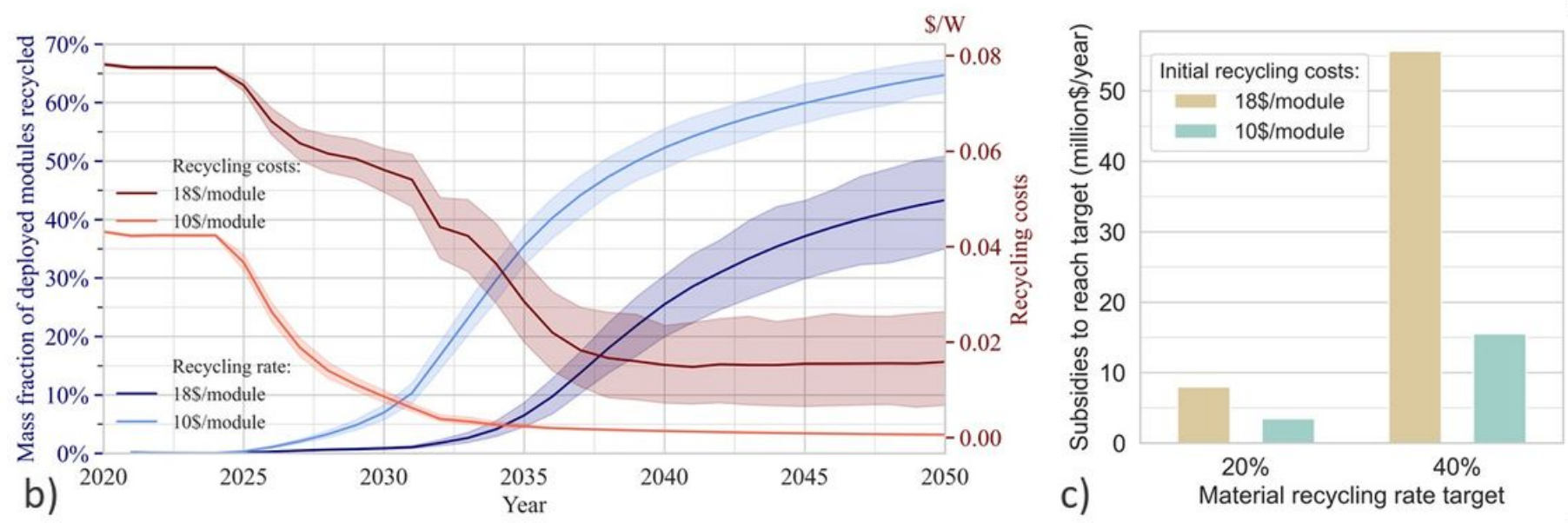

\section{Figure 3}

a) Cumulative materials from EOL PV modules and recycler net income assuming use of the FRELP process and an initial recycling cost of $\$ 18 /$ module. The dip in recycler net income is due to initially unprofitable recycling. Still, with the low initial recycling cost and high recovery of materials (including silver and silicon), recycler cumulative net income reaches $\$ 1.6$ billion, and net income is $\$ 0.42 / \mathrm{kg}$, in 2050. b) Cumulative recovered material value in 2050. High materials recovery and low initial recycling costs have a synergistic effect on value generation, but the synergy diminishes as the initial recycling costs is very high or very low. For instance, at an initial recycling cost of $\$ 16 /$ module, a $13 \%$ increase from an $80 \%$ material recovery fraction roughly doubles the recovered material value. 

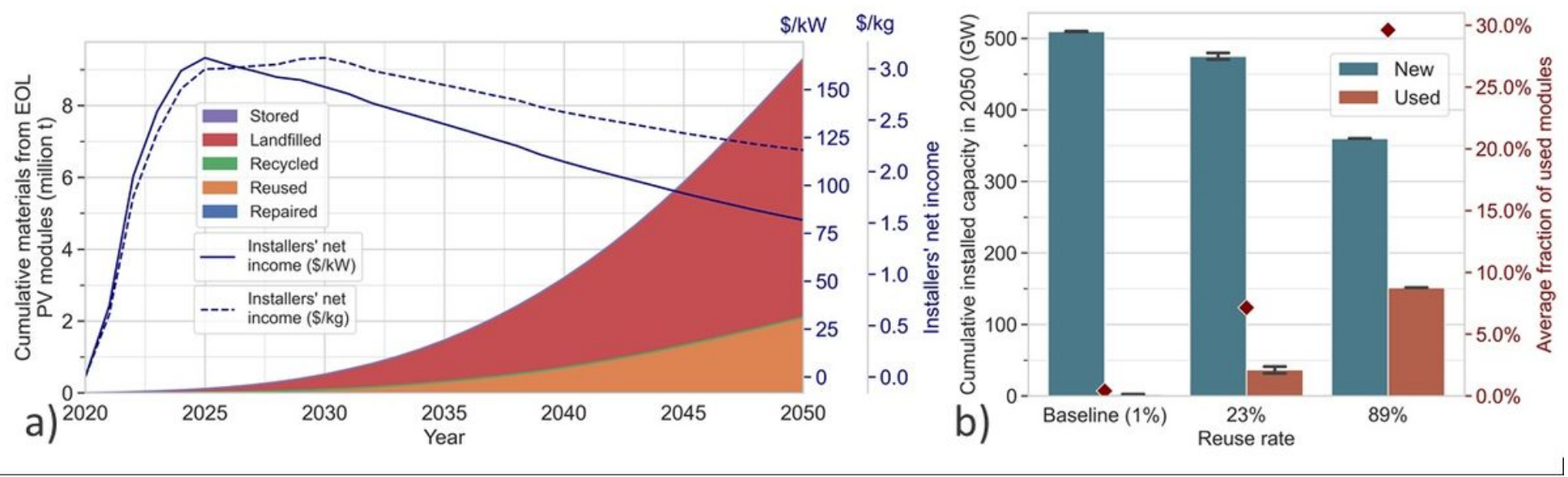

\section{Figure 4}

a) Cumulative materials from EOL PV modules and installer net income assuming improved warranties give PV owners an equivalent attitude toward used and new modules, showing substantial module reuse. Installer cumulative net income is $\$ 3.5$ billion, and net income is $\$ 2.2 / \mathrm{kg}$, in 2050 . After 2025 , the net income per module decreases as innovation reduces PV module costs. b) Cumulative installed capacities of used and new modules in 2050 for various reuse rates obtained with our simulations; red diamonds represent the average fraction of used modules. In an ideal reuse case (89\% reuse bars in the Figure), modules landfilled after their second life represent almost $10 \%$ of the cumulative EOL PV modules in 2050. Error bars represent $95 \%$ confidence intervals.

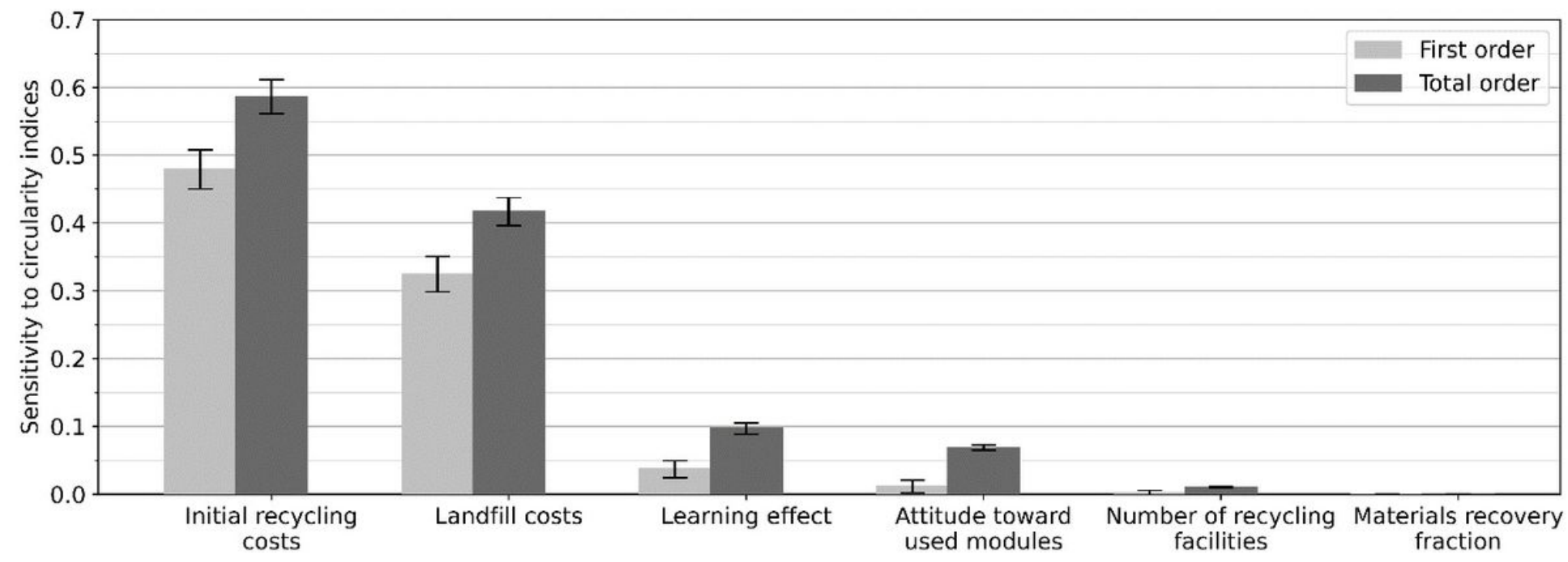

\section{Figure 5}

Parameter importance for EOL PV module circularity in the ABM, categorical parameters such as the landfill ban excluded. The y-axis shows the first- and total-order Sobol indices on the effect of a parameter on EOL PV module circularity. Error bars show 95\% confidence intervals. 


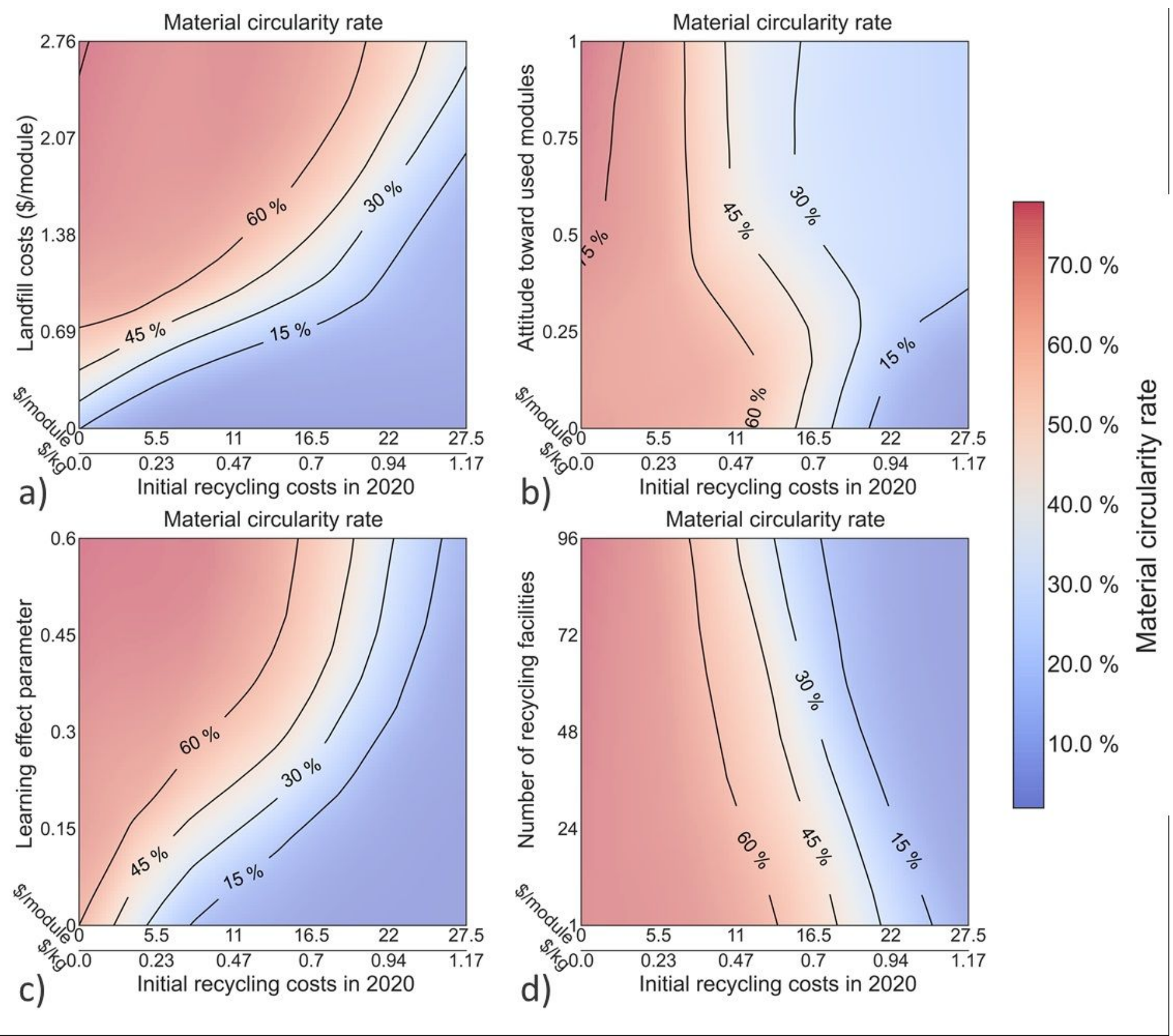

Figure 6

Parameter importance for EOL PV module circularity in the ABM, categorical parameters such as the landfill ban excluded. The y-axis shows the first- and total-order Sobol indices on the effect of a parameter on EOL PV module circularity. Error bars show 95\% confidence intervals.

\section{Supplementary Files}

This is a list of supplementary files associated with this preprint. Click to download.

- IntegratingSocialFactorsPVrecyclingXreuselnterventionsWalzbergetalSupplementaryMaterial.docx

- SupplementaryFile2.xlsx 